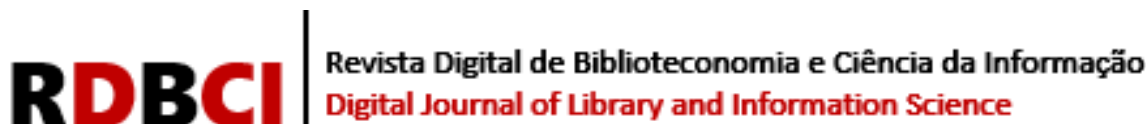

IS.S $1678-765 x$

$10.20396 /$ rdbci.v19ioo.8664607

(c) (i) $B Y$

ARTIGO

\section{Limitações do acesso à informação sobre contratação pública em saúde no Brasil à luz da Lei de Acesso à Informação \\ uma revisão integrativa da literatura}

\author{
Virgínia de Albuquerque Mota ${ }^{1}$ (ID) https://orcid.org/0000-0003-2331-3926 \\ Rogério Henrique de Araújo Júnior 2 (ID https://orcid.org/ 0000-0002-6125-822X \\ ${ }^{1}$ Universidade Federal de Mato Grosso, Cuiabá, MT, Brasil / e-mail: virginia.a.mota@gmail.com \\ ${ }^{2}$ Universidade de Brasília, Brasília, DF, Brasil / e-mail: rogerio.araujo.jr@gmail.com
}

\begin{abstract}
RESUMO
Introdução: Investigar as limitações do acesso às informações sobre contratação pública em saúde no Brasil, no período de 1990 a 2018, de acordo com critérios definidos na Lei de Acesso à Informação. Método: Revisão integrativa da produção científica publicada em periódicos indexados no período supramencionado, com análise dos registros de limitações relatados na busca do acesso às informações sobre contratação pública em saúde, considerando os critérios previstos na referida Lei para garantir o acesso de: primariedade, integridade, atualização, disponibilização e autenticidade. Resultados: Foram incluídos 35 artigos na revisão, com predomínio de estudos sobre a fase externa do processo de contratação pública em saúde, complexidade do objeto de contratação de bens e tendo como contratante as esferas federal e municipal. Identificou-se 64 fontes de informação, sendo a maioria fontes secundárias, no formato de bancos e bases de dados, e 43,75\% destas fontes apresentaram relato de limitações em relação ao acesso às informações obtidas. Conclusão: $O$ acesso às informações sobre contratação pública em saúde apresenta limitações importantes em relação à Lei de Acesso à Informação, e tem repercussões sobre a produção do conhecimento científico. A Ciência da Informação pode contribuir com estudos futuros para qualificar os processos de busca e recuperação da referida informação.
\end{abstract}

PALAVRAS-CHAVE

Acesso à informação. Informação governamental. Fonte de informação. Saúde coletiva. Revisões de literatura.

\section{Limitations on public health procurement information access in Brazil under the Information Access Law \\ a literature integrative review}

\section{ABSTRACT}

Introduction: Investigate the limitations of public procurement information health access in Brazil, from 1990 to 2018, according to Access to Information Law criteria. Method: Integrative review was carried out on published scientific production in indexed journals, with analysis of the limitations reported in the search for public procurement information health access, considering the criteria provided for in that Law to guarantee access: primacy, integrity, updating, availability and authenticity. Results: 35 articles were included in the review, with a predominance of studies on the external phase of the public health procurement process, complexity of the object of contracting goods and having the federal and municipal spheres as contractor. 64 information sources were identified, the majority being secondary sources, in the format of banks and databases, and $43.75 \%$ of these sources reported limitations regarding access to the information obtained. Conclusion: Public procurement information 


\section{RDBCI}

health access has important limitations in relation to the criterias of Access to Information Law, and has repercussions on the production of scientific knowledge. Information Science can contribute to future studies to qualify the search and retrieval processes for that information.

\section{KEYWORDS}

Information access. Public information. Information sources. Health expenditure. Literature reviews.

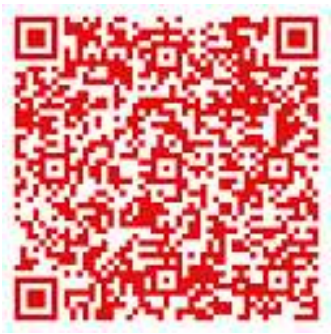

JITA: BA. Use and impact of information. 


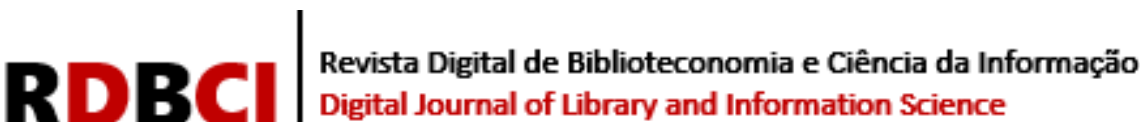

\section{INTRODUÇÃO}

A contratação pública é um processo complexo, que envolve Estado e sociedade, e objeto de estudo de inúmeras investigações e de recomendação de organismos internacionais, preocupados com a racionalidade dos gastos públicos e a sustentabilidade financeira ao redor do mundo.

Esta atenção é justificada pela estimativa de que, a cada três dólares de gastos públicos no mundo, um dólar seja empregado em contratações públicas (OPEN CONTRACTING PARTNERSHIP, 2018), e que em um contexto macroeconômico de crise financeira e políticas de ajuste fiscal, o acesso às informações referentes a estes gastos são fundamentais para o aperfeiçoamento da gestão pública.

Segundo Attard et al. (2015), o acesso de dados governamentais abertos em paísesmembros da União Europeia possui limitações no acesso em relação a diferenças de conteúdo, barreiras semânticas, de acessibilidade e do formato dos dados. No Brasil, o mesmo estudo constatou que a centralização da administração dos sistemas de informação pelo governo federal contribui para a padronização destas informações, mas a incorporação de novas tecnologias para garantir o acesso não ocorre tempestivamente.

Basu et al. (2012) realizaram uma revisão sistemática da literatura para comparar critérios de desempenho entre sistemas de saúde públicos e privados de países de renda baixa e média, sendo um desses critérios a transparência e acesso às informações, e constataram que é escassa a publicização dos dados de parcerias público-privadas, em especial dos prestadores privados, e como consequência não permite a avaliação dos serviços prestados ao sistema de saúde oficial nos contextos estudados.

No Brasil, historicamente, houve uma negligência no investimento da consolidação de uma rede própria do Sistema Único de Saúde (SUS), ao mesmo tempo em que houve financiamento público da rede privada, o que culminou no quadro atual de dependência da administração pública em relação aos serviços privados em várias localidades e subsetores da saúde (VIACAVA et al., 2018). Nesses casos, a carência de informações sobre a contratação pública reflete o desconhecimento sobre a realidade do próprio sistema de saúde.

A ausência de acesso às informações relativas à contratação pública na saúde traz repercussões para todo o sistema, na medida em que afetam diretamente a qualidade do atendimento prestado, a lógica da atenção à saúde, a capacidade de investimento do SUS, dentre outros.

Podemos considerar que a gênese dessas dificuldades tem relação com o acesso às informações, configurando-se como um problema relevante para o campo da Ciência da Informação (CI), relacionadas desde o nível macro, de ausência de uma política para informações sobre contratação pública na saúde e de delimitação normativa e teórica sobre quais são as informações necessárias sobre contratação pública, até o nível micro, de ausência de profissionais de informação e de uma cultura de não utilizar estrategicamente as referidas informações para a tomada de decisão.

Uma estratégia internacional para a promoção da transparência governamental na contratação pública seria a melhoria da qualidade do acesso aos dados, até para conhecimento da totalidade de possíveis gargalos de desperdícios financeiros, em espaços nos quais esses dados seriam analisados, como as audiências públicas ou assembleias locais de avaliação, desde as necessidades de contratação até prestação de contas do cumprimento ou não dos contratos, entre outros (MACKEY et al., 2016).

Neste cenário, a CI pode contribuir para discussão sobre o acesso à informação, visto que este campo do conhecimento surgiu justamente da necessidade de tratar um grande volume 


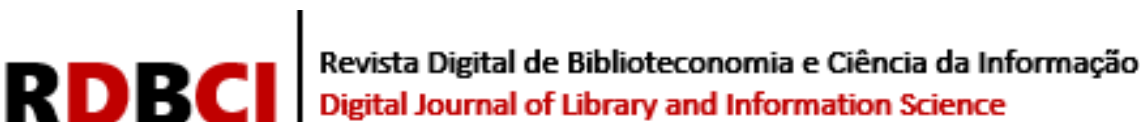

de informações e conhecimentos científicos do período pós-guerra. Bush (1945) entendia que todo arsenal de informações produzidas até então eram elementos estratégicos para subsidiar os processos decisórios, no entanto se a informação pertinente para os que delas necessitassem não estivessem acessíveis, isto representaria um atraso no desenvolvimento da própria ciência.

Desta forma, as organizações podem utilizar de forma mais eficiente as informações produzidas e recebidas por elas, mas que pela ausência de visão sobre o caráter estratégico destas para a tomada de decisão, acabam tornando-se massas documentais acumuladas, sem aplicação prática nem como subsídio à tomada de decisão, nem como memória organizacional.

Diante da complexidade do processo de contratação pública e do papel fundamental da transparência governamental para a melhoria do gerenciamento dos recursos em saúde, estudos apontam a necessidade de desenvolvimento de pesquisas sobre as informações relacionadas aos contratos (MATOS; POMPEU, 2003) e às atividades administrativas envolvidas nos processos de contratação (COTTA et al., 2009).

Apesar desta relevância, são poucos os estudos que avaliam a qualidade do acesso às informações sobre contratação pública em saúde no SUS, ainda que haja registros sobre a existência dessas limitações e que estas impactem substancialmente tanto nos resultados das pesquisas científicas quanto na elaboração do planejamento em saúde pela administração pública.

Neste contexto, este estudo tem como objetivo investigar as limitações em relação ao acesso às informações sobre contratação pública em saúde no Brasil, em uma revisão integrativa da literatura, no período do início de implementação do SUS com sua regulamentação através das leis orgânicas da saúde (1990) até o ano de 2018, no qual são completados os 30 anos do "SUS constitucional", e que são necessárias análises desse período histórico para avançarmos na consolidação do sistema de saúde, e em especial da contratação pública que representa um dos pontos sensíveis que dificultaram essa consolidação (PAIM, 2018).

A revisão integrativa é considerada a "pesquisa das pesquisas" e configura-se como um método de revisão de literatura muito utilizado na área da saúde, que pode incluir estudos com diferentes metodologias para atender diferentes finalidades, como revisar evidências sobre variáveis ainda pouco exploradas como objetos centrais de pesquisa, sendo importante que estas estejam bem definidas pelo propósito da revisão e a partir de um parâmetro que permita comparação destas variáveis em diferentes publicações (WHITTEMORE; KNAFF, 2005).

\section{CIÊNCIA DA INFORMAÇÃO E ACESSO À INFORMAÇÃO}

A informação é tomada como objeto de uma grande diversidade de campos de conhecimento ao longo da história da humanidade, no entanto somente a partir da metade do século XX que se estrutura formalmente uma disciplina que pretende tratar da informação como seu objeto central de estudo, denominada Ciência da Informação.

Bush (1945) coloca que, no contexto de guerra fria no qual havia um grande volume de informações produzidas durante as duas grandes guerras, era necessária a gestão estratégica destas informações, para garantir o acesso às mesmas e recuperação das informações que poderiam ser subsidiar tomada de decisão e desenvolvimento científico, e dar sentido a todo esforço científico e técnico empreendido em retorno para a sociedade.

O primeiro conceito formal de CI é cunhado por Borko (1968, p.3), em documento que marca a mudança da nomenclatura da "American Documentation Institute" para "American Society for Information Science", no qual define CI como "[...] disciplina que investiga as propriedades e comportamento da informação, as forças governando o fluxo das informações e o significado de processar a informação para ótima acessibilidade [...]”. 


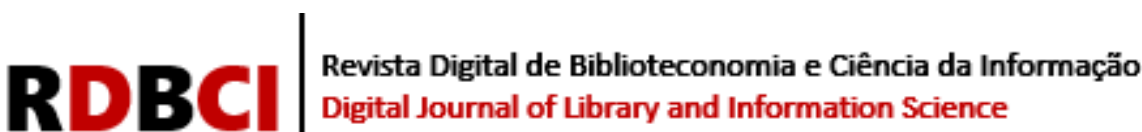

Configurando-se como uma ciência social aplicada, a CI depara-se com problemas relacionados ao acesso aos grandes volumes de dados e informações, que não se dá somente pela disponibilização dos estoques informacionais, mas sim pelo tratamento e organização das informações que facilite a sua recuperação de acordo com as necessidades informacionais dos usuários.

O acesso às informações governamentais remonta a própria sistematização deste campo, primeiramente voltado para facilitar o processo de recuperação da informação científica acumulada, e também na organização e tratamento das informações produzidas e custodiadas pelo Estado, na perspectiva da transparência governamental.

Nos últimos anos, as autoridades públicas adotaram medidas de incremento do acesso às informações governamentais. Em 2011, o Brasil e mais sete países fundaram um comitê diretor internacional nomeado Open Government Partnership (OGP), quando foi apresentado um plano de dados abertos com o compromisso de ampliação da transparência governamental (FREITAS; DACORSO, 2014).

Como principal desdobramento deste plano, tivemos a aprovação da Lei $\mathrm{n}^{\circ} 12.527$, de 18 de novembro de 2011 (BRASIL, 2011), conhecida como Lei de Acesso à Informação (LAI), que regulamentou o acesso à informação cujo direito já constava no texto da Constituição Federal de 1988, passando a publicização a ser a regra e o sigilo a exceção na esfera federal, estadual e municipal (FERREIRA et al., 2012). Essa legislação tem como consequência avanços importantes em convergência com alguns pontos do supramencionado consenso internacional.

Nesta legislação e no arcabouço normativo que derivou dela, tais como o Decreto 7.724, de 16 de maio de 2012 (BRASIL, 2012), temos o conceito de transparência ativa e passiva, sendo que na transparência ativa a administração pública deve tornar as informações governamentais acessíveis para toda a sociedade e na transparência passiva a administração pública deve fornecer todas as informações que forem solicitadas (FERREIRA et al., 2012).

De acordo com este instrumento legal, os critérios de acesso à informação foram definidos segundo o artigo $4^{\mathrm{o}}$ :

\begin{abstract}
VI - disponibilidade: qualidade da informação que pode ser conhecida e utilizada por indivíduos, equipamentos ou sistemas autorizados; VII - autenticidade: qualidade da informação que tenha sido produzida, expedida, recebida ou modificada por determinado indivíduo, equipamento ou sistema; VIII - integridade: qualidade da informação não modificada, inclusive quanto à origem, trânsito e destino; IX primariedade: qualidade da informação coletada na fonte, com o máximo de detalhamento possível, sem modificações (BRASIL, 2011).
\end{abstract}

O estabelecimento de critérios e um conjunto normativo posterior à esta legislação, contribuiu para que o Brasil ocupasse a oitava posição entre os países com dados abertos no mundo em levantamento do Open Data Global Index (OKI, 2018). Segundo este mesmo levantamento, dados de parcerias público-privadas não se encontram no formato aberto (nãoprocessados por máquinas, não-download de uma só vez, não atualizados e não disponíveis para acesso público).

As limitações do acesso às informações sobre parcerias público-privadas, que são uma forma de contratação pública, têm relação com a organização das referidas informações em fontes que permitam o acesso, considerando os critérios definidos na legislação. 


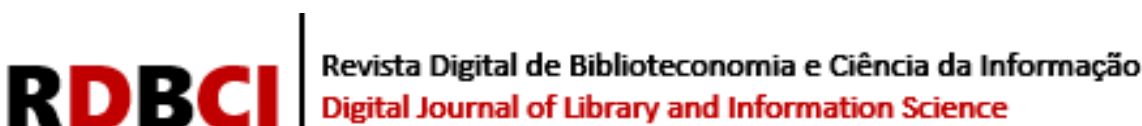

\section{CONTRATAÇÃO PÚBLICA EM SAÚDE E FONTES DE INFORMAÇÃO}

Para além da ausência da disponibilização de informações relevantes, observa-se que entendimentos convergentes do que é contratação pública, quais são suas etapas e qual é o papel dos profissionais que atuam diretamente nesse processo, também contribui para a organização, gestão e recuperação da informação sobre a referida contratação (PRIER; MCCUE, 2009).

Organismos internacionais definem contratação pública como um processo complexo, composto pelas etapas de: i) levantamento da demanda; ii) escolha da melhor resposta a essa demanda, iii) estabelecimento de contratação firmada pelos Estados Partes com objetivos governamentais; iv) acompanhamento; v) avaliação; e vi) prestação de contas; e essas etapas são apoiadas nos preceitos de competição, economia, eficiência, justiça e transparência das informações (MERCOSUL, 2017; OECD, 2015; WTO, 2014).

Para Mendes (2012), no Brasil, tanto nos textos legais e normativos quanto na prática, o processo de contratação pública, que se estrutura desde o planejamento do setor até a fiscalização da execução do contrato, tem sido equivocadamente tratado de forma parcial, com grande ênfase na licitação (fase externa) e em menor ênfase nas demais fases do referido processo. Para demarcar essa estruturação, o autor propõe a definição da contratação pública como:

\begin{abstract}
"Conjunto de fases, etapas e atos estruturados de forma lógica para permitir que à Administração, a partir da identificação precisa da sua necessidade e demanda, possa definir com precisão o encargo desejado, minimizar seus riscos e selecionar, isonomicamente, se possível, a pessoa capaz de satisfazer sua necessidade pela melhor relação custo-benefício" (MENDES, 2012, p. 25).
\end{abstract}

Durante o período definido como recorte temporal desta pesquisa (1990 a 2018), o processo de contratação pública no Brasil foi regido pela Lei n. 8.666/1993, que considera contrato "[...] todo e qualquer ajuste entre órgãos ou entidades da administração pública e particulares, em que haja acordo de vontade para formação de vínculo e a estipulação de obrigações recíprocas, seja qual for a denominação utilizada [...]”, e pode ser consumado por intermédio de diferentes modalidades de aquisição, definidos pelo Art. 22 da mesma legislação, como concorrência, tomada de preços, convite, concurso ou leilão (BRASIL, 1993).

$\mathrm{Na}$ Figura 1, estão representados os 3 aspectos do processo de contratação pública (PCP) considerados por Mendes (2012) para a compreensão do seu conceito, quais sejam os pilares que dão sustentação ao processo, a complexidade do objeto contratado e as fases interna, externa e contratual, que englobam as ações a serem desenvolvidas durante o referido processo.

Figura 1- Pilares, complexidade do objeto e fases do processo de contratação pública.

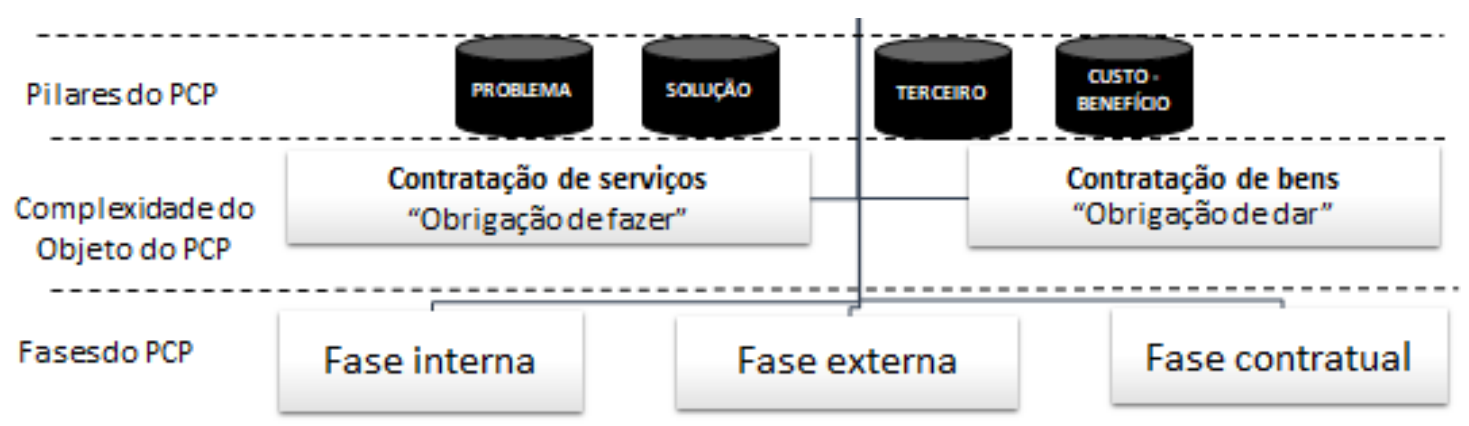

Fonte: elaboração própria, baseada em Mendes (2012). 


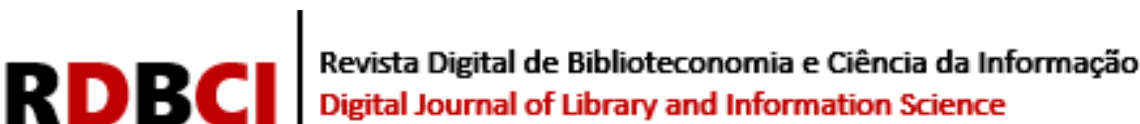

A fase interna do PCP relaciona-se com o planejamento, que contempla desde a identificação da necessidade até a elaboração do edital; a fase externa compreende as etapas de seleção da proposta vencedora para atender a necessidade pública; e a fase contratual compreende a execução do encargo e sua respectiva remuneração, bem como fiscalização e controle (MENDES, 2012).

As informações governamentais, especificamente aquelas relacionadas à contratação pública em saúde, são estratégicas para os processos de tomada de decisão que envolve desde o levantamento da real necessidade de contratação até a avaliação do custo-benefício da modalidade de contratação para a demanda da administração pública.

No contexto da saúde brasileira, o tratamento dos dados contratuais iniciou-se na década de 1970, com a instituição pelo governo federal de mecanismo de controle da prestação de serviço privado para a administração pública, chamado "Autorização de Internação Hospitalar". Esse mecanismo tinha como finalidade o combate às fraudes e posteriormente, já no âmbito do SUS, foi integrado ao Sistema de Informações Hospitalares (SIH), que se mantém até o presente momento.

A implementação dos primeiros sistemas de informação em saúde, incluindo o SIH, mantiveram a finalidade da gestão da informação em saúde para administração gerencial pelo ente federal dos procedimentos produzidos e/ou contratados pelos entes estaduais e municipais. Os principais desafios desses primeiros sistemas foram sua fragmentação, com retrabalho e informações conflitantes sobre o mesmo objeto, e a ausência de rigor e padronização na sua alimentação (MORAES, 1994).

Parte desses desafios verificados no início da implementação do SUS relacionam-se com a organização do próprio SUS e com a gestão compartilhada entre os três entes da federação (municípios, estados e federal), que contribuem com a alimentação das fontes de informação sobre contratação pública disponíveis de forma não padronizada.

Como apontado acima, o SIH/SUS não foi concebido inicialmente como Sistema de Apoio à Decisão (SATD), e sim como sistema de processamento de transações, responsáveis pela consolidação da produção assistencial das unidades hospitalares, para posterior ressarcimento contratual pela administração pública.

No entanto, a ausência de informações acessíveis para subsidiar os processos decisórios, e em especial de planejamento em saúde, conduziu tanto técnicos quanto pesquisadores à utilização dos dados disponibilizados no SIH/SUS (e em outros sistemas concebidos com finalidades similares) como fontes de informação para se conhecer a contratação pública em saúde.

Esses sistemas, dentre outros repositórios, bancos de dados, relatórios e demais documentos técnicos e de pesquisa, são configurados como fontes de informação sobre contratação pública em saúde, e a CI vem contribuindo com a classificação dessas fontes de informação, estratégias para promoção da transparência e acesso à informação tempestiva e oportuna, a organização da informação e do conhecimento voltado para o atendimento das necessidades dos usuários, entre outros, entendimento este convergente com a Política Nacional de Informação e Informática em Saúde (BRASIL, 2016).

As fontes de informação podem ser classificadas como: (i) fontes primárias, consideradas aquelas que contém informações inéditas ou novas interpretações de dados notórios; (ii) fontes secundárias, consideradas aquelas que apresentam informações primárias reorganizadas para o receptor; e (iii) fontes terciárias, que contribuem para a recuperação de informações primárias e secundárias. Conforme Quadro 1, estes tipos de fontes possuem formatos específicos, de acordo com a utilização das informações contidas (CUNHA, 2001). 


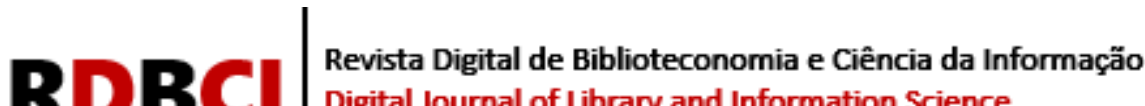 Digital Journal of Library and Information Science}

Quadro 1. Tipos e formatos de fontes de informação.

\begin{tabular}{|c|l|}
\hline TIPO & \multicolumn{1}{|c|}{ FORMATO } \\
\hline Primária & $\begin{array}{l}\text { Congressos e conferências, legislação, nomes e } \\
\text { marcas comerciais, normas técnicas, patentes, } \\
\text { periódicos, projetos e pesquisas em andamento, } \\
\text { relatórios técnicos, teses e dissertações e traduções }\end{array}$ \\
\hline Secundária & $\begin{array}{l}\text { Bases e bancos de dados, bibliografias e índices, } \\
\text { biografias, catálogos de bibliotecas, centros de } \\
\text { pesquisa e laboratórios, dicionários e enciclopédias, } \\
\text { dicionários bilíngues e multilíngues, feiras e } \\
\text { exposições, filmes e vídeos, fontes históricas, livros, } \\
\text { manuais, internet, museus, herbários, arquivos e } \\
\text { coleções científicas, prêmios e honrarias, redação } \\
\text { técnica e metodologia científica, siglas e abreviaturas, } \\
\text { tabelas, unidades, medidas e estatísticas, artigos de } \\
\text { revisão }\end{array}$ \\
\hline Terciária & $\begin{array}{l}\text { Bibliografias de bibliografias, bibliotecas e centros de } \\
\text { informação }\end{array}$ \\
\hline
\end{tabular}

Fonte: elaboração própria, baseada em Cunha (2001)

Conhecer as fontes de informação e suas finalidades é importante para investigar as potenciais limitações em relação ao acesso às informações, no entanto em razão da escassez de produção científica especificamente com a temática do acesso à informação sobre contratação pública em saúde, define-se a busca das limitações sobre o referido acesso nos registros das comunicações científicas que investigaram o mesmo objeto de pesquisa.

A revisão integrativa mostrou-se como a técnica de pesquisa mais adequada, por este tipo de revisão caracterizar-se como uma estratégia de recuperação de informações que não são centrais ou relacionadas ao objeto de pesquisa inicial dos artigos revisados. Neste estudo, os artigos incluídos na revisão têm diferentes objetivos, mas em todos eles há uma discussão sobre a coleta e a análise de informações sobre contratação pública em saúde, e em parte deles há relatos de limitações do acesso à informação, que é o objeto de pesquisa do presente trabalho.

As vantagens em trabalhar com a revisão de artigos indexados em bases é a garantia da revisão pelos pares e de que existe avaliação Qualis dos periódicos científicos promovida pela Coordenação de Aperfeiçoamento de Pessoal de Nível Superior (Capes), de acordo com as áreas de conhecimento. Este sistema de avaliação Qualis, que tem impacto na pontuação dos programas de pós-graduação e no financiamento de pesquisas, foi a forma encontrada para não reduzir a avaliação da produção acadêmica aos aspectos quantitativos (BARATA, 2016).

No entanto, Pires et al. (2020) observaram que a avaliação Qualis Capes também vem conformando a produção científica brasileira, uma vez que os pesquisadores, vinculados à pósgraduação principalmente, direcionam seus esforços para publicação em periódicos de melhor pontuação, seguindo os escopos delimitados dos temas de interesse e linhas editoriais.

Ainda assim, apesar dos possíveis vieses da utilização de uma revisão de literatura como estratégia metodológica, este artigo busca compreender as limitações que os pesquisadores se depararam no acesso à informação sobre contratação pública no contexto do SUS através dos registros nas publicações científicas. 


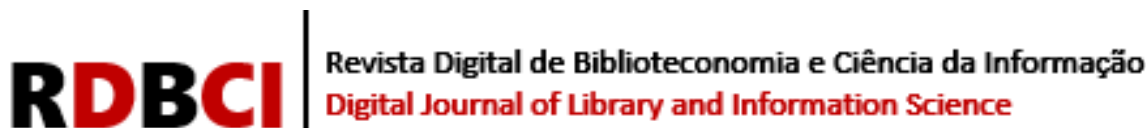

\section{PROCEDIMENTOS METODOLÓGICOS}

A pesquisa se utiliza da revisão integrativa com a finalidade de investigar um problema ainda pouco explorado na literatura científica, como é o caso das limitações do acesso às informações sobre contratação pública em saúde, em um conjunto de publicações científicas que coletaram as referidas informações (SOUZA et al., 2010), detalhado no Quadro 2.

Os dados coletados dos artigos científicos incluídos nesta revisão referem-se aos registros das limitações enfrentadas para conseguir acesso às informações sobre contratação pública em saúde, de acordo com critérios apontados pela Lei de Acesso à Informação (BRASIL, 2011), quais sejam: disponibilidade, autenticidade, integridade, primariedade e atualização.

Quadro 2. Roteiro para a revisão integrativa.

\begin{tabular}{|c|c|}
\hline FASES DA REVISÃO INTEGRATIVA & $\begin{array}{l}\text { REVISÃO INTEGRATIVA SOBRE LIMITAÇÕES DO } \\
\text { ACESSO AS INFORMAÇÕES SOBRE } \\
\text { CONTRATAÇÃO PÚBLICA EM SAÚDE NO BRASIL }\end{array}$ \\
\hline Pergunta norteadora & $\begin{array}{l}\text { Quais são as limitações do acesso às informações } \\
\text { sobre contratação pública em saúde no Brasil } \\
\text { utilizadas nas publicações científicas? }\end{array}$ \\
\hline Busca ou amostragem na literatura & $\begin{array}{l}\text { Artigos completos disponíveis em formato digital } \\
\text { sobre contratação pública em saúde no Brasil, } \\
\text { publicados no período de } 1990 \text { a 2018, nas bases de } \\
\text { dados Periódico Capes, PubMed, Web of Science, } \\
\text { BVS/BIREME, Scopus, DOAJ, ISTA e LISTA, com } \\
\text { ocorrência dos termos em inglês ou português: } \\
\text { ("contratação pública" OR contrato OR "parcerias } \\
\text { público-privadas" OR relação público-privada") AND } \\
\text { ("sistema de saúde" OR "saúde pública") AND Brasil, } \\
\text { que atendem aos critérios de inclusão. }\end{array}$ \\
\hline Coleta de dados & $\begin{array}{l}1^{\text {a }} \text { etapa: seleção dos artigos pela leitura dos resumos; } \\
\text { período de coleta: abril a junho de 2019; e } \\
2^{\text {a }} \text { etapa: seleção dos artigos pela leitura de texto } \\
\text { completo, com preenchimento do instrumento de } \\
\text { coleta de dados. }\end{array}$ \\
\hline Análise dos estudos incluídos & $\begin{array}{l}\text { Categorias de análise: I - Características do artigo } \\
\text { (base de dados, área de conhecimento do periódico, } \\
\text { ano, vínculo institucional dos autores e método de } \\
\text { pesquisa); II - Características do Processo de } \\
\text { Contratação Pública (fases, complexidade do objeto e } \\
\text { esfera de gestão); III - Características das fontes de } \\
\text { informação (tipo de fontes e dados coletados); e IV - } \\
\text { Características do acesso às informações } \\
\text { (disponibilidade, autenticidade, integridade, } \\
\text { primariedade e atualização). }\end{array}$ \\
\hline Discussão dos resultados & $\begin{array}{l}\text { Pretende-se discorrer sobre as categorias analisadas a } \\
\text { partir do registro que os autores fazem dos temas } \\
\text { abordados, analisar à luz de autores que discutiram } \\
\text { qualidade das fontes de informação em saúde (não } \\
\text { especificamente sobre contratação pública em saúde), }\end{array}$ \\
\hline
\end{tabular}




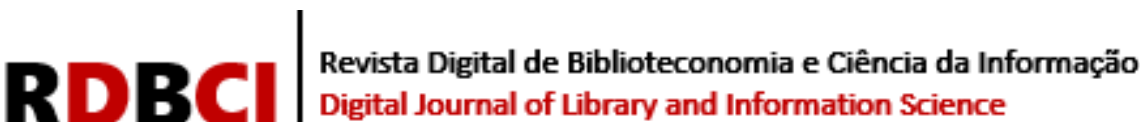

para vislumbrar possíveis lacunas do conhecimento e indicar possibilidades de pesquisa neste tema.

Fonte: dados da pesquisa (2020)

A coleta dos dados foi realizada em duas etapas, nos meses de abril a junho de 2019, sendo na primeira etapa a seleção dos artigos a serem incluídos na revisão, e na segunda etapa a aplicação de um instrumento de pesquisa para coleta de dados nos artigos selecionados.

Na primeira etapa foram selecionados artigos sobre contratação pública no âmbito do SUS, publicados no período de 1990 a 2018, revisados por pares e indexados nas bases de dados: Bireme/BVS (Biblioteca Virtual em Saúde), MEDLINE (Medical Literature Analysis and Retrieval System Online), Web of Science, Scopus, LILACS (Literatura Latino-Americana e do Caribe em Ciências da Saúde), ISTA (Information Science \& Technology Abstracts) e LISTA (Library, Information Science \& Technology Abstracts).

A escolha das bases Bireme/BVS, MEDLINE e LILACS justifica-se por serem bases especializadas em publicações na área da Ciências da Saúde, as bases ISTA e LISTA por serem bases especializadas em publicações na área da Ciência da Informação e as bases Web of Science e Scopus por serem bases interdisciplinares de grande relevância para as áreas de Ciências da Saúde e Ciências Sociais Aplicadas. Estas bases também possuem em seus repositórios artigos de periódicos e autores de diferentes nacionalidades.

Os critérios para seleção dos artigos na primeira etapa são os que apresentaram nos campos: título, palavras-chave ou resumo, os termos na língua portuguesa e inglesa: ((“contratação pública” OR contrato OR "parcerias público-privadas" OR "relação públicoprivada") AND ("sistema de saúde" OR "saúde pública") AND Brasil). O operador boleano OR foi utilizado para contemplar os diferentes termos que representam o tema de interesse desta revisão, uma vez que ainda não existe consenso na literatura acadêmica unificando a referida representação e o operador boleado AND foi utilizado para delimitar a abrangência dos processos de contratação pública.

Para inclusão nesta primeira etapa, foram analisados os resumos e identificados os artigos originais que atendem aos objetivos do trabalho, quais sejam pesquisas que coletaram nas diferentes fontes as informações sobre, pelo menos, uma das fases (interna, externa ou contratual) do processo de contratação pública no setor saúde, tendo o Estado como contratante e pelo menos uma entidade privada (pessoa jurídica) como contratada.

Foram excluídos os documentos que não apresentaram dados sobre contratação pública em saúde no Brasil, cuja coleta de dados tenha sido exclusivamente entrevista e/ou revisão, não tenham descrito as respectivas fontes de informação e/ou dados e informações coletados e não tenha o texto completo disponível para acesso público.

Foram selecionados 35 artigos na primeira etapa, e a partir da leitura do texto completo destes, na segunda etapa foram coletadas as informações definidas no instrumento de coleta de dados (Quadro 3), com a finalidade de conhecer os artigos, caracterizar os processos de contratação pública analisados, determinar as fontes de informações utilizadas e as limitações do acesso à informação sobre contratação pública em saúde no Brasil. 


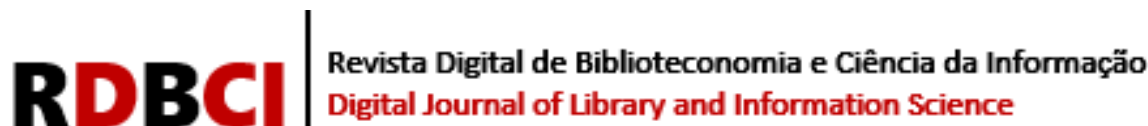

Quadro 3. Instrumento de coleta de dados.

\begin{tabular}{|c|c|c|c|}
\hline BLOCOI & BLOCO II & BLOCO III & BLOCO IV \\
\hline Características dos artigos & $\begin{array}{l}\text { Características do } \\
\text { Processo de } \\
\text { Contratação } \\
\text { Pública }\end{array}$ & $\begin{array}{l}\text { Características das } \\
\text { fontes de informação }\end{array}$ & $\begin{array}{l}\text { Características do acesso à } \\
\text { informação }\end{array}$ \\
\hline $\begin{array}{l}\text { Base de dados; } \\
\text { Área de conhecimento da } \\
\text { CAPES; } \\
\text { Ano de publicação; } \\
\text { Vínculo institucional dos } \\
\text { autores; } \\
\text { Método de pesquisa. }\end{array}$ & $\begin{array}{l}\text { Fases; } \\
\text { Complexidade do } \\
\text { objeto; } \\
\text { Esfera de gestão } \\
\text { do SUS: federal, } \\
\text { estadual, distrital } \\
\text { ou municipal }\end{array}$ & $\begin{array}{l}\text { Tipos: primárias, } \\
\text { secundárias ou } \\
\text { terciárias; } \\
\text { Formato; } \\
\text { Dados coletados }\end{array}$ & $\begin{array}{l}\text { Disponibilidade; } \\
\text { Autenticidade; } \\
\text { Integridade; } \\
\text { Primariedade; } \\
\text { Atualização }\end{array}$ \\
\hline
\end{tabular}

Fonte: dados da pesquisa (2020).

A caracterização dos artigos seguiu o seguinte roteiro: análise segundo base de dados, área de conhecimento do periódico (segundo classificação da CAPES), ano de publicação, estratégia metodológica empregada (quantitativa, qualitativa ou quanti-qualitativa) e vínculo dos autores. Quando autores indicavam mais de um vínculo institucional, considerou-se a instituição relacionada no artigo na qual o autor estava empregado.

Em relação à caracterização do processo de contratação pública em saúde presente nos artigos selecionados, foram verificadas as fases do processo de contratação pública (interna, externa e/ou contratual), complexidade do objeto (contratação de bens, contratação de serviços ou contratação de bens e/ou serviços) e esfera da gestão do SUS (federal, estadual, distrital ou municipal).

Na sequência, foram relacionadas as fontes de informação sobre contratação pública em saúde utilizadas nos artigos, a frequência dos tipos de fontes (primária, secundária ou terciária) e as características de acesso à informação registrada nos artigos, a partir dos categorias definidas na Lei n. ${ }^{\circ} 12.257$ (BRASIL, 2011), que são: disponibilidade (acessível para indivíduos e máquinas); autenticidade (identificação do indivíduo, sistema ou equipamento responsável por produção, expedição, recebimento ou modificação); integridade (sem alterações referentes à origem, tramitação e destinação); e primariedade (detalhamento máximo possível, sem tratamento).

\section{RESULTADOS E ANÁLISES}

\subsection{Caracterização dos artigos}

Nas sete bases de dados pesquisadas foram localizados 35 artigos que atenderam aos critérios de inclusão e exclusão em 5 bases de dados, referentes ao período de 2003 a 2018. A consulta às bases se deu na sequência apresentada no Gráfico 1 , sendo eliminadas as ocorrências de artigos repetidos. 


\section{Devista Digital de Biblioteconomia e Ciência da Informação

\section{Gráfico 1. Frequência absoluta de artigos por base de dados e ano de publicação.}

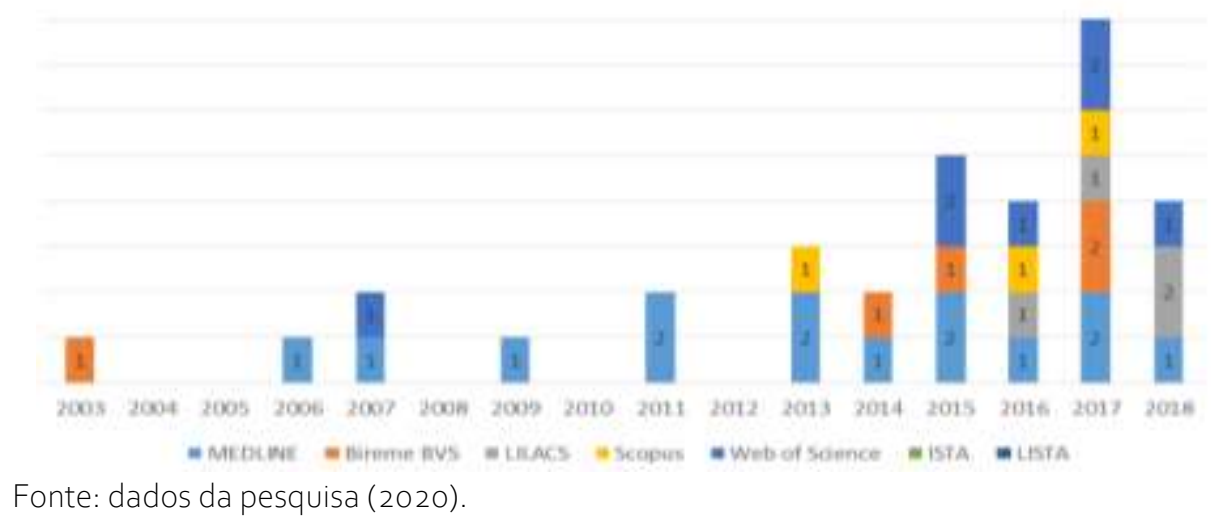

Em relação às áreas de conhecimento dos periódicos dos artigos selecionados, 18 eram da área exclusiva de Ciências da Saúde, sendo o periódico com mais artigos incluídos a "Ciência \& Saúde Coletiva" (7), e redigiram estes artigos 119 autores de 35 instituições diferentes, que foram agrupadas em 11 tipos de instituição (Gráfico 2).

Em alguns casos, autores de mais de uma instituição redigiram o mesmo artigo (que foi considerado uma vez por instituição, mesmo se houvesse mais de um autor da mesma instituição), por isto o número total de artigos do Gráfico 2 excede o total de 35 artigos.

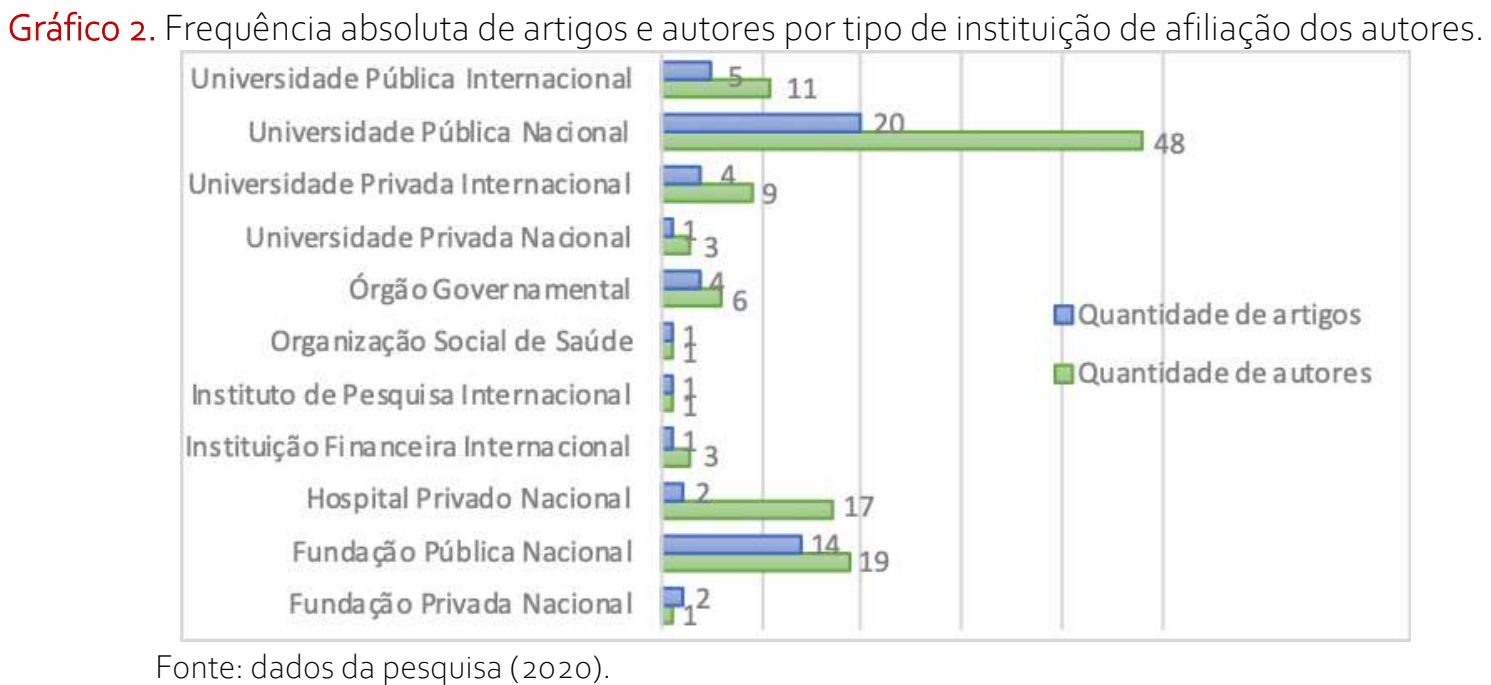

A maioria dos autores são vinculados às universidades ou fundações, destacando-se também na produção da maioria dos artigos. Esta quantidade pode ser explicada tanto pela publicação científica ser critério de aferição do desempenho docente, quanto pela vinculação de outros atores a estes docentes em cursos de pós-graduação, como já apontado na Introdução deste artigo.

Observa-se também a participação de autores vinculados aos órgãos governamentais, organização social de saúde e hospital privado, ainda que com abordagens diferentes. Enquanto autores vinculados aos órgãos governamentais abordaram temas relacionados à necessidade de aumento de eficiência do processo de contratação pública, autores vinculados a organização social de saúde ressaltaram vantagens da contratação pública destas entidades e autores vinculados a hospital privado abordaram a diferença entre os gastos do referido hospital na prestação do serviço contratado em relação ao reembolso do contratante (gestor do SUS). 


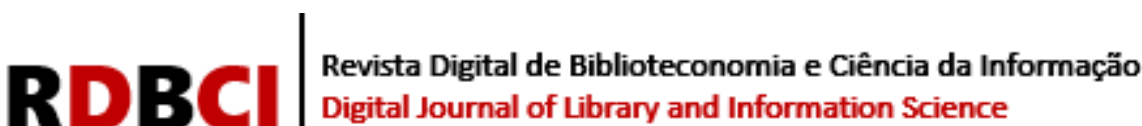

Dentre as publicações internacionais, nove possuíam autores com vínculos em instituições internacionais, a maioria com o tema da compra de medicamentos em países em desenvolvimento.

Do total de 35 estudos, quatro utilizaram pesquisas qualitativas, quatro pesquisas quanti-qualitativas e 27 pesquisas quantitativas. Predominaram nos estudos quantitativos a utilização de dados secundários disponíveis para acesso público (gastos, preços máximos, quantidades adquiridas, previsões orçamentárias, prestações de contas, despesas com pessoal, quantidade de estabelecimentos contratados, custos hospitalares, custos com material, previsão de consumo, número de pessoas atendidas, transferências financeiras, entre outros), apoiados por pesquisa documental e pesquisa bibliográfica.

\section{2 Caracterização do processo de contratação pública em saúde}

Dos 35 artigos incluídos nesta revisão, apenas dois contemplaram informações que poderiam subsidiar a identificação de necessidade pública (primeira etapa da fase interna), com levantamento de informações contidas em atas de colegiado de gestão do SUS e meios de comunicação de massa (FONSECA; COSTA, 2015), e com análise de impacto orçamentário de diferentes possibilidades de solução para atendimento de uma demanda específica (ELIAS et al., 2015).

Este fato pode estar relacionado tanto com à ausência de interesse científico e/ou acadêmico sobre a fase interna do PCP, quanto à ausência de dados e informações disponíveis sobre esta fase, ou até mesmo ausência de sistematização de ações por parte da administração pública em relação à identificação de necessidades públicas, análise de viabilidade técnica e econômica sobre as possíveis soluções para atender estas necessidades e elaboração de edital de seleção de terceiros com o melhor custo-benefício para os usuários do SUS, entre outras etapas desta primeira fase.

Oito artigos analisaram a fase externa, com objetivo de verificarem fatores relacionados a possíveis desperdícios de recursos ou vantagem financeira para a administração pública durante a realização de procedimentos licitatórios ou pregões (DIAS et al., 2013; FREITAS; MALDONADO, 2013), com comparação entre preços praticados por período, por local (entre entes da federação ou nacional e internacional) e de tabelas de preços máximos, disponíveis no Banco de Preços em Saúde (Ministério da Saúde) ou Câmara de Regulação do Mercado de Medicamentos (ANVISA).

Em relação à fase externa da contratação de bens, como aquisição de medicamentos por exemplo, estudos apontaram que, apesar do processo de descentralização do SUS ter aproximado o gestor das necessidades públicas no território onde estas se conformam, foi limitada a capacidade de barganha da administração pública com a perda de escala, podendo ser mais vantajosa para a administração a centralização no nível federal da aquisição dos medicamentos (FONSECA; COSTA, 2015; ARAÚJO et al., 2017).

Associadas à fase externa da contratação pública, as Parcerias de Desenvolvimento Produtivo (PDP) objetivavam a transferência de tecnologia e crescimento da autonomia na produção pública de bens estratégicos para o país (MORAES et al., 2016), e teve consequências também na redução de preço e possibilidade de atendimento de outras demandas na fase contratual (CHAVES et al., 2018), demonstrando a capacidade do Estado em enfrentar o lobby da indústria farmacêutica.

Tabela 1. Complexidade do objeto e esfera de gestão, segundo fase do processo de contratação pública investigadas nos artigos.

RDBCl: Rev. Dig. Bibliotec e Ci. Info. / RDBCl: Dig. J. of Lib. and Info. Sci. | Campinas, SP | v.19| e021011 | 2021 


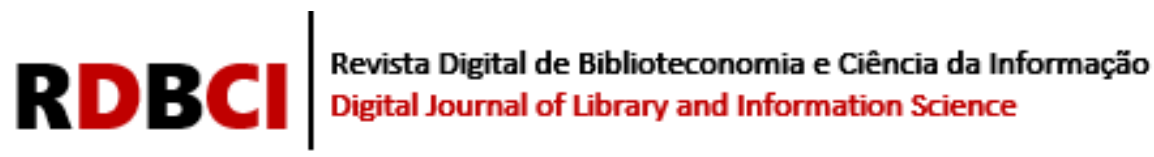

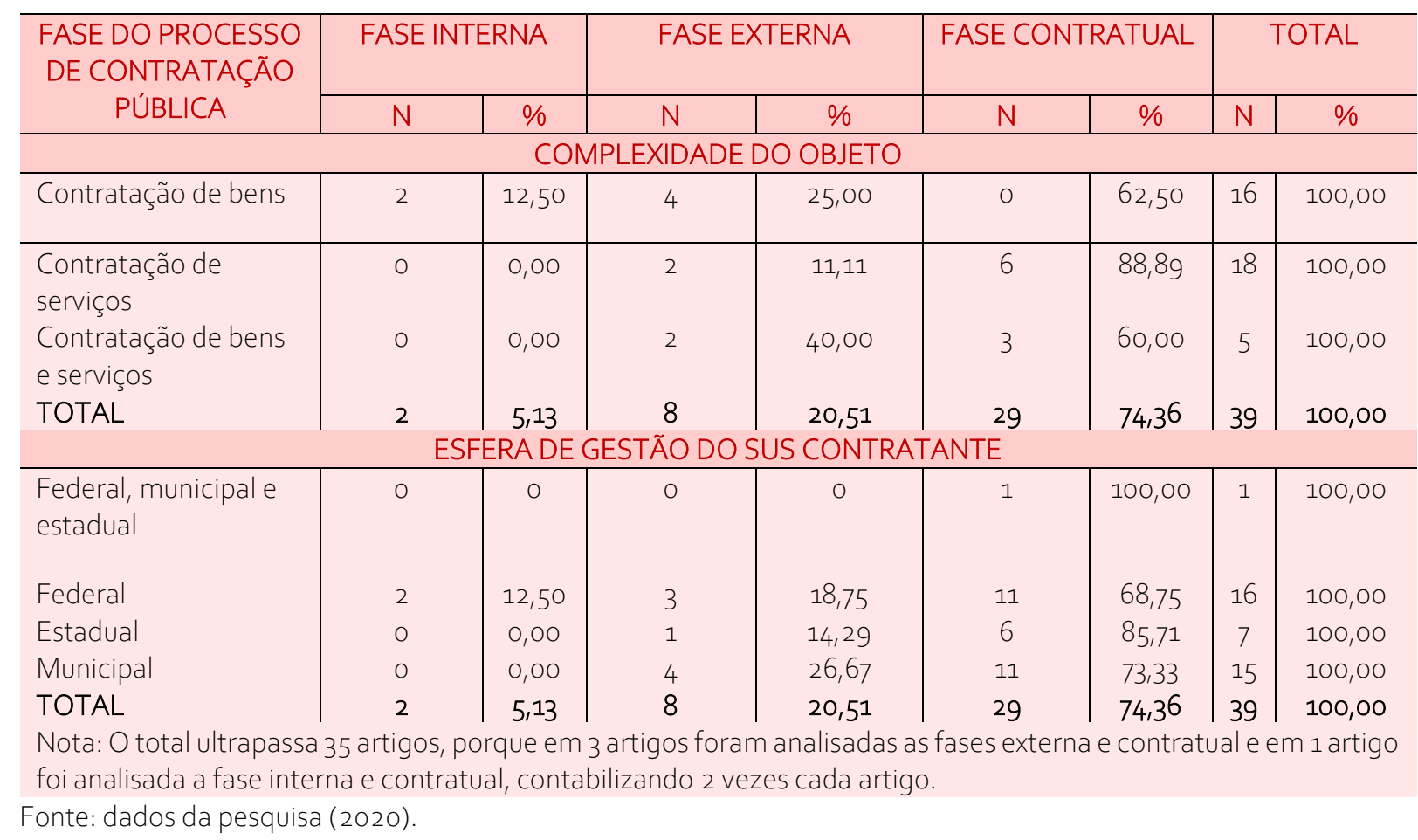

Em relação aos artigos da fase contratual, historicamente existia dificuldade de formalização contratual (MATOS; POMPEU, 2003), que decorre do poder político do setor privado, incluindo o filantrópico, no padrão de definição dos objetos dos contratos, alinhado a uma política de Estado de fortalecimento do modelo de contratação, em detrimento da oferta direta de ações e serviços de saúde (SILVA; CAETANO, 2018; ROMANO; SCATENA, 2014; CONTREIRAS; MATTA, 2015; NUNES; PAIVA, 2016). Ainda assim, Sugulem e Zucchi (2009) observaram que a utilização de ferramentas de tecnologia da informação para sistema de compra conjunta representou avanços na eficiência da gestão das contratações públicas em saúde.

O poder político do setor privado referido não pode ser confundido por poder políticopartidário, uma vez que McGregor et al. (2017) verificaram a estabilidade da contratação independente de resultados eleitorais e das bandeiras defendidas pelos diferentes partidos políticos nacionais, indicando que uma possível relação de poder desigual entre o setor privado e a administração pública consolida as práticas de contratação pública em saúde independente de fatores externos.

A dificuldade de acesso aos dados e informações e de adequada regulação e controle na fase contratual do instrumento formal que rege a relação do Estado com as Organizações Sociais de Saúde foram reportadas por diversos autores (SILVA et al., 2016; IRELAND et al., 2016; CONTREIRAS; MATTA, 2015), e tem repercussões sobre a participação e controle social e na avaliação do custo-benefício dessa modalidade de gestão em relação à administração direta.

Especificamente sobre os gastos, Morais et al. (2018) analisaram o incremento dos valores globais dos contratos com Organizações Sociais de Saúde entre 18,2 e 87,9\%, a partir de celebração de termos aditivos, no período de 2009 a 2014, e que em virtude desses incrementos, os valores dos termos aditivos também são relevantes para serem adicionados nas avaliações de custo-benefício, pois podem representar montantes diversos dos inicialmente contratados. 


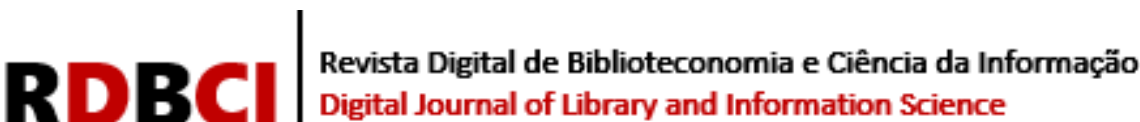

Sobre a contratação de serviços profissionais, Barbosa (2017) destacou a discrepância entre a dinâmica organizacional e a base de dados disponível para acesso, concluindo que esta base não refletia todos os aspectos a serem considerados para uma possível avaliação dos serviços contratados.

Kaliks et al. (2013) reforçaram as diferenças de gastos do setor privado para a prestação do serviço contratado em relação à remuneração do setor público, devido à desatualização da "Tabela SUS" ou do Sistema de Gerenciamento da Tabela de Procedimentos, Medicamentos e OPM (DESGUALDO et al., 2011), e diferenças desses setores também em relação à agilidade e qualidade do atendimento das demandas (LANSKY et al., 2007; MENDES et al., 2014), entre outros.

As parcerias público-privadas, articuladas pelo Ministério da Saúde, tanto na assistência farmacêutica (Programa Farmácia Popular do Brasil) quanto na provisão de serviços médicos (Programa Mais Médicos), demonstram aumento de acesso (EMMERICK et al., 2015; SILVA et al., 2018), mas com dificuldades de estimar o custo-benefício devido à ausência de dados e/ou informações.

$\mathrm{Na}$ fase contratual, a entrega do encargo e a remuneração de medicamentos também têm maior frequência entre os objetos de PCP investigados nos artigos selecionados, visto que o Brasil é o sétimo mercado farmacêutico do mundo (HOMMA et al., 2013). Estes artigos apresentavam como objetivo a avaliação de estratégias para redução de gastos (MEINERS et al., 2011; CAMPOS; FRANCO, 2017) e maior barganha em situações de monopólio (CHAVES et al., 2017), incremento de transparência no PCP, alinhamento de diferentes políticas de assistência farmacêutica (BEVILACQUA et al., 2011), entre outros.

A política de abastecimento de doses de vacina e de medicamentos antirretrovirais são cases de sucesso na contratação pública em saúde, relacionada tanto com pressão exercida pelos movimentos sociais no enfrentamento da epidemia de AIDS no Brasil, quanto com estratégias de aquisição centralizada e política de autossuficiência de produção de vacinas, que permitiu a utilização da contratação como complementar (HOMMA et al., 2013), e pelo caráter preventivo da vacinação, permitiu quantificar exatamente a demanda, ainda que se observe a ausência de controle efetivo da cobertura de vacinação e da utilização de doses.

O sucesso nas ações preventivas é crucial, principalmente na perspectiva do sistema de saúde brasileiro, que ainda não conseguiu efetivar políticas intersetoriais de intervenção sobre os determinantes sociais do processo saúde-doença e cuja população sofre com os gastos privados diretos em saúde, em sua maioria gastos com medicamentos.

Além dos gastos privados diretos com medicamentos pela população, ressalta-se também o impacto das fraudes e corrupção nas aquisições públicas, resultando em medicamentos mais caros em países de alta renda e em escassez de medicamentos em países de média e baixa renda (MACKEY, 2016).

No Brasil, o acesso aos medicamentos deve ser garantido principalmente por uma política de gestão eficiente de recursos coordenada pelo nível federal, devido ao contexto de desigualdades socioeconômicas entre os níveis de gestão do SUS (PONTES et al., 2017; KOHLER et al., 2015).

Em relação à fiscalização dos contratos, Dias et al. (2013) contribuem com a necessidade de implantação de mecanismos de combate ao desperdício passivo, relacionado à má gestão, dentre eles a transparência no processo de contratação pública, que pode ser qualificada com acesso às informações sobre contratação pública em saúde disponíveis e que podem aproximar (ou afastar) os cidadãos, pesquisadores, usuários, trabalhadores, gestores, prestadores de serviços, entre outros, da realidade da participação privada no SUS.

5. 3 Caracterização das fontes de informação

RDBCl: Rev. Dig. Bibliotec e Ci. Info. / RDBCl: Dig. J. of Lib. and Info. Sci. | Campinas, SP | v.19| e021011 | 2021 


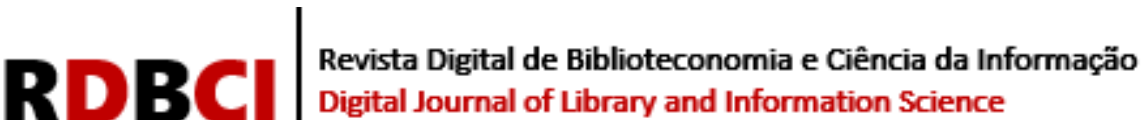

Nesta revisão, foram identificadas 64 diferentes fontes de informação utilizadas nos artigos analisados, para coleta de dados e/ou informações sobre contratação pública em saúde, com dados coletados referente ao período de 1981 a 2018.

\begin{tabular}{l|l|l|l} 
Tabela 2. Frequência dos tipos e formatos das fontes de informação. \\
\hline \multicolumn{1}{c|}{ TIPO DE FONTE } & \multicolumn{1}{|c}{ FORMATOS DE FONTE } & \multicolumn{2}{|c}{ FREOUENCIA } \\
\cline { 2 - 4 } & & $\mathrm{N}$ & $\%$ \\
\hline Primária & Legislação & 3 & 4,69 \\
Primária & Normas técnicas & 2 & 3,13 \\
Primária & Periódicos & 2 & 3,13 \\
Primária & Projetos e pesquisas em andamento & 2 & 3,13 \\
Primária & Relatórios técnicos & 6 & 9,38 \\
Secundária & Bases e bancos de dados & 28 & 43,75 \\
Secundária & Internet & 17 & 26,56 \\
Secundária & Livros & 2 & 3,13 \\
Terciária & Revisões de Literatura & 2 & 3,13 \\
\hline TOTAL & & 64 & 100,00 \\
\hline
\end{tabular}

Fonte: dados da pesquisa (2020).

As fontes secundárias são as mais utilizadas, representando mais de $70 \%$ das fontes (Tabela 2), sendo somente em bases e bancos de dados 43,75\%, com maior frequência dos sistemas de informação sob gestão do Ministério da Saúde, seguidas por internet $(26,56 \%)$. Muitos destes sistemas de informação em saúde foram concebidos anteriormente à Lei de Acesso à Informação (BRASIL, 2011), como ferramenta auxiliar para gerenciamento de dispêndios públicos em saúde.

Além de não terem sido concebidos para apoiar o processo decisório da gestão em saúde, Moraes (1994) afirma que na implantação destes sistemas, estes foram subutilizados ou reportados como de qualidade inadequada pelos próprios responsáveis na sua alimentação e manutenção.

Quando analisados os artigos incluídos nesta revisão integrativa, verifica-se que, em sua maioria, eles também reproduzem as informações dos sistemas de informação em saúde governamentais, e que também coexistem, ainda que em menor quantidade, estudos que as informações sobre contratação pública têm origem em bancos de dados privados das entidades contratadas.

Verifica-se a utilização dos bancos de dados privados quando os pesquisadores possuem vínculos empregatícios com as instituições cujas informações são analisadas nos artigos (GONZÁLEZ; CALIMAN, 2018; MENDES et al., 2014; KALIKS et al., 2013), sendo que estes artigos destacam como pontos relevantes as vantagens da contratação pública e/ou defasagem dos valores ressarcidos pela administração pública aos serviços e/ou bens contratados em relação aos valores praticados no mercado privado.

Para que esta aproximação seja ainda mais fidedigna, a qualidade da fonte de informação das quais estes autores buscaram subsídios para defender ou refutar suas teses é ainda mais importante. No entanto, enquanto alguns periódicos possuem seção exclusiva para o relato das limitações do estudo, onde usualmente os autores pontuam as características em relação às fontes de informação, outros periódicos publicam artigos sem menção das referidas limitações. 


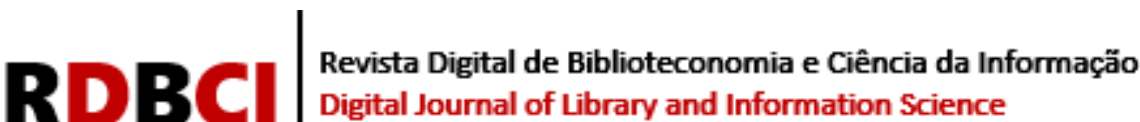

\section{4 Caracterização do acesso à informação}

Das 64 fontes identificadas, 28 (43,75\%) tiveram limitações relacionadas à qualidade da transparência (primariedade, integridade, atualização, disponibilidade e autenticidade) das informações coletadas registradas pelos autores e autoras nos artigos incluídos nesta revisão.

Em relação aos relatórios técnicos, projetos e pesquisas em andamento, apesar de serem fontes primárias, houve vários apontamentos sobre limitações em relação à primariedade, como informações baseadas em ausência de documentos (DIAS et al., 2013), ausência de padronização da informação registrada nos relatórios técnicos das fontes de informação das quais os dados foram retirados (CONTREIRAS; MATTA, 2015; NUNN et al., 2007) e dificuldade em decompor as informações apresentadas (NUNN et al., 2007).

As fontes secundárias, como as bases e bancos de dados (sistemas de informação em saúde principalmente) e sites de internet de instituições públicas e privadas, também apresentaram limitações quanto a fragmentação das informações agregadas, como diferenciação entre medicamentos genéricos e similares ou tipos de fornecedores de medicamentos no Banco de Preços em Saúde (KOHLER et al., 2015).

Já em relação à Lista de Preços-teto da Câmara de Regulação do Mercado de Medicamentos, houve registro em relação à determinação de preços-teto de medicamentos distintos para o mesmo medicamento, dependendo do fornecedor (CAMPOS; FRANCO, 2017).

Ainda referindo-se aos medicamentos, nos registros do Programa Aqui Tem Farmácia Popular (ATFP) e de acesso ao Componente Especializado da Assistência Farmacêutica, os apontamentos relacionam-se à ausência de registro por estabelecimento, independentemente de ser matriz ou filial, e ausência de detalhamento dos valores, tipo de medicamento e quantidade comercializados ou dispensados individualmente (SILVA; CAETANO, 2018; FONSECA; COSTA, 2015).

Não são disponibilizadas em atas de registro de preço e sistemas de gerência de estoque (fonte secundária disponível na internet) dados do fabricante e nome comercial dos medicamentos (BEVILACQUA et al., 2011).

Apesar do Sistema de Informações Hospitalares (SIH) possuir no seu banco a discriminação entre estabelecimentos públicos e estabelecimentos privados conveniados ao SUS, Matos e Pompeu (2003) apontaram que esta diferenciação não é possível em relação aos hospitais universitários.

O Sistema de Informações sobre Orçamentos Públicos em Saúde (SIOPS) não permitiu Araújo et al. (2017) estimarem os gastos próprios reais do ano de 2010, porque as informações registradas neste sistema eram as despesas empenhadas e não as pagas, da mesma forma que sites oficiais da internet (CONTREIRAS; MATTA, 2015) também não permitiram identificar pagamentos a entidades, quando estes vêm discriminados pela natureza da despesa somente.

Em relação à integridade das informações, as fontes primárias no formato de projetos e pesquisas em andamento apresentaram fragilidade por não relatarem todos os itens da composição de custos para formulação de estimativas de gastos, quando comparados aos bancos oficiais (KALIKS et al., 2013).

As fontes secundárias, no formato de base e bancos de dados, possuem fragilidade em relação à ausência de metodologia disponível para alimentação dos bancos como o Banco de Preços em Saúde, que são realizadas pelos gestores do SUS que realizaram a aquisição (SIGULEM; ZUCCHI, 2009), uma vez que o referido banco é formatado em campos de livre preenchimento (CAMPOS; FRANCO, 2017).

A diferença na discriminação da informação do Programa ATFP e do Componente Básico da Atenção Básica, que são programas concorrentes, não permite a comparação entre os 


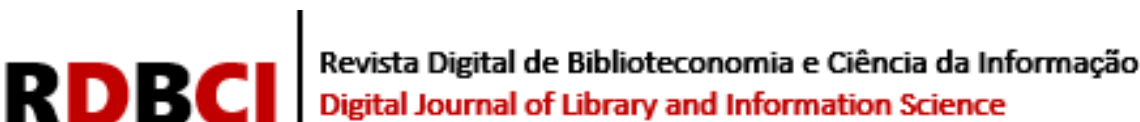

custos das duas estratégias de ampliação de acesso a medicamentos básicos para a população (SILVA; CAETANO, 2018).

Sistema de informação mais utilizado nos estudos desta revisão, o Sistema Cadastro Nacional de Estabelecimentos de Saúde (SCNES) deve fornecer dados sobre os estabelecimentos de saúde, vínculos profissionais, habilitações e contratos de serviços nos referidos estabelecimentos, e ainda tem interoperabilidade com outros bancos que são utilizados para coleta de informações sobre produção assistencial própria e contratada, como o Sistema de Informações Ambulatoriais (SIA) e o SIH.

Apesar de ser um sistema fundamental para coleta de informação sobre contratação pública, nos artigos desta revisão foram relatadas como limitações para utilização do SCNES a ausência de registro, que frustraram o acesso à produção assistencial de prestadores privados de serviço contratados para atuar em estabelecimentos da rede própria do SUS (MATOS; POMPEU, 2003; GONZÁLEZ; CALIMAN, 2018; GREVE; COELHO, 2017).

A falta de preenchimento de campos dos sistemas de informação de saúde tem relação com a diversidade de atores no nível local que realizam a alimentação de dados dos referidos sistemas, o que tem repercussões diretas sobre a completude e qualidade das informações, e como a gestão desses sistemas é centralizada no nível federal, os resultados apresentados não conseguem identificar as informações sobre contratações públicas em saúde em todos os níveis de gestão (MORAES et al., 2016; PONTES et al., 2017).

Em relação à atualização das informações, especificamente sobre a contratação pública dos bens "medicamentos", observa-se que fontes secundárias de registro de preços praticados pela administração pública, que poderiam servir de parâmetro para os valores praticados no mercado, sofrem influências que não são consideradas pelos respectivos bancos, como o tempo de mercado do medicamento e a quantidade adquirida por cada compra (ELIAS et al., 2015).

Foram relatadas também desatualização de páginas web em sites oficiais de gestores do SUS criadas especificamente para promover transparência dos processos de contratação pública na saúde, implicando na busca por informação em outras fontes que contém documentos que atendem parcialmente as necessidades de informação específicas dos pesquisadores do setor saúde (SILVA et al., 2016; GREVE et al., 2017).

Ao mesmo tempo em que faltaram informações recentes em fontes de informação utilizadas nos artigos desta revisão, havia informações de contratos no SCNES, cuja data de vigência excedia o prazo legal de até 5 anos para renovação de contratos (MATOS; POMPEU, 2003).

Em razão da defasagem de valores indicados nos bancos de dados utilizados como parâmetro para reembolso de serviços prestados ao SUS, os referidos valores tornam-se fictícios, impossibilitando a aproximação real dos custos com contratação pública para o setor saúde, com utilização de complementação financeira dos entes federativos (ROMANO; SCATENA, 2014), prática de valores muito acima da tabela (MENDES et al., 2014) e ausência de registro dos valores reais praticados pela administração pública.

Ainda sobre valores praticados, relatórios técnicos que têm por finalidade estimar custos para planejamento de contratação pública em saúde, sofrem de atualizações necessárias para as referidas estimativas, como variações de câmbio e outros impactos nos preços ao tempo da efetivação do gasto (MORAES et al., 2016; CHAVES et al., 2017).

Outra questão que impacta sobre a atualização das informações sobre contratação pública em saúde é a não obrigatoriedade da alimentação de alguns bancos e bases de dados ou a ausência de informação sobre o lapso temporal entre a aquisição e o consumo (PONTES et al., 2017; NUNN et al., 2017).

RDBCl: Rev. Dig. Bibliotec e Ci. Info. / RDBCl: Dig. J. of Lib. and Info. Sci. | Campinas, SP | v.19| e021011 | 2021 


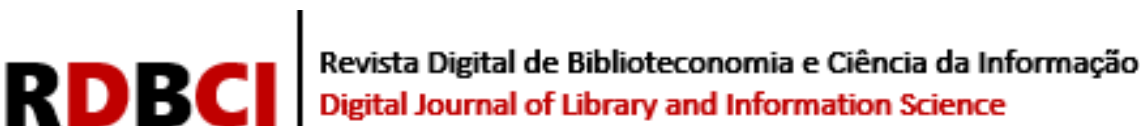

Em relação à disponibilização das informações sobre contratação pública em saúde referidas nos estudos que compõem esta revisão, verifica-se que fontes primárias como relatórios técnicos, que se propõem a realizar levantamentos no território nacional, não conseguem disponibilizar dados da totalidade de municípios brasileiros (SILVA et al., 2018).

Mesmo fontes secundárias, como bancos e bases de dados, não disponibilizam a totalidade dos dados ou na totalidade do período de funcionamento do SUS em que havia contratação pública (SILVA et al., 2018; CAMPOS; FRANCO, 2017; ARAÚJO et al., 2017; MORAES et al., 2016; SILVA et al., 2016; NUNN et al., 2007; MATOS; POMPEU, 2003), ou até mesmo são disponibilizados dados nos locais onde existem melhores indicadores de qualidade do SUS, em detrimento de locais com indicadores piores.

A ausência de dados em locais onde existem piores indicadores de qualidade do SUS deve ser corrigida, porque são os dados que subsidiam decisões que podem qualificar os referidos indicadores (LANSKY et al., 2007) e informações sobre bens e/ou serviços que faltam, bem como o tempo deste desabastecimento ou ausência de cobertura de assistência à saúde, também são fundamentais para um planejamento mais eficiente, efetivo e eficaz (MEINERS et al., 2011).

Quando existe substituição em alguma prática relacionada ao processo de contratação pública, não são disponibilizados os estudos de análise do possível impacto positivo destas propostas de alterações, como por exemplo na inclusão do pregão eletrônico na fase externa do referido processo (FREITAS; MALDONADO, 2013), ou mesmo quando um novo programa é instituído em razão de lacunas na assistência, a ausência de informações prévias fragilizam a comparação das situações antes e depois da implementação desses programas (SILVA et al., 2018), e a avaliação do seu custo-benefício.

Os documentos relacionados com a prestação de contas, que poderiam subsidiar informações sobre contratação pública na saúde, em alguns casos não estão disponibilizados nos bancos e bases de dados nem da administração pública e nem dos órgãos de controle interno e externo, e isto fragiliza também o exercício do controle social (MORAIS et al., 2018; SILVA et al., 2016; NUNES; PAIVA, 2016; CONTREIRAS; MATTA, 2015).

Em razão desta ausência de disponibilidade de informações, vários pesquisadores recorreram aos Serviços de Informação ao Cidadão (SILVA; CAETANO, 2018; CHAVES et al., 2018; CONTREIRAS; MATTA, 2015; FONSECA; COSTA, 2015), ainda que a verificação das informações obtidas fossem de difícil conferência (SILVA; CAETANO, 2018), o que implica no questionamento da autenticidade dessas informações por ausência de dados sobre possíveis alterações do material desses serviços no fluxo da informação, e que, ainda que respaldados pela legislação, houve dificuldade em obter respostas satisfatórias, por conta da incompletude ou indisponibilidade dos dados (NUNES; PAIVA, 2016).

Ainda referindo à ausência de disponibilidade, pesquisadores foram para campo fazer coleta das informações que necessitavam e que não localizaram nos sistemas de informação (BARBOSA, 2017), ou ainda realizaram estimativas de custos com base nos instrumentos legais e normativos (SILVA et al., 2018), que representa o que deveria acontecer, e não o que realmente foi gasto no processo de contratação pública estudado.

Observa-se agradecimentos às pessoas e/ou instituições que forneceram os dados (MORAES et al., 2016) e pessoas do setor público que tinham vínculo profissional e obtiveram facilidade de acesso (EMMERICK et al., 2015; FREITAS; MALDONADO, 2013), estabelecendo-se requisitos para o referido acesso quando este deveria ser público.

Em alguns casos, a ausência de informações disponíveis pode ser justificada pela aplicação de instrumentos legais e normativos na contratação pública em saúde elaborados para regulamentar outros setores da administração pública, como a Lei de Licitação n. ${ }^{\circ}$ 8.666/1993 (BRASIL, 1993), que inicialmente foi elaborada para serviços da área de construção civil, e a 


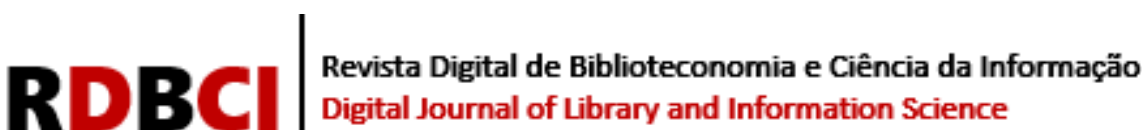

despeito destes instrumentos, a adequação do processo de contratação à uma cultura organizacional hegemônica que influenciou suas regras (MATOS; POMPEU, 2003).

Além dos instrumentos e cultura organizacional, observa-se que entendimentos distintos do que é contratação pública, quais são suas etapas e qual é o papel dos profissionais que atuam diretamente nesse processo, também contribui negativamente para a recuperação da informação sobre a referida contratação (PRIER; MCCUE, 2009).

Outras dificuldades de acesso à informação também foram relatadas pelos autores dos artigos que compõem essa revisão, tais quais as possibilidades dos dados existentes ofertarem uma panorama ou a construção de uma estimativa, mas impossibilitarem produzir afirmações sobre a contratação pública em saúde no Brasil (NUNN et al., 2007; MATOS; POMPEU, 2003), falta de informatização no registro dos dados e informações (FONSECA; COSTA, 2015), centralização da gestão e organização dos dados pelo Ministério da Saúde por este ser a principal fonte de financiamento público (SILVA; CAETANO, 2018), não padronização dos dados disponibilizados em relação ao mercado internacional, que inviabiliza comparações do modelo de contratação pública brasileira a outros modelos (MEINERS et al., 2011), entre outros.

Além das contribuições para pensarmos a qualidade da transparência das informações sobre contratação pública no âmbito do SUS, os artigos revisados também apontam lacunas quanto à avaliação da qualidade dos serviços contratados e metodologias possíveis de serem empregadas para a avaliação da referida qualidade, associadas à comparação de taxas de mortalidade por exemplo (LANSKY et al., 2007; GREVE et al., 2017), o regular cumprimento do contrato firmado (FREITAS; MALDONADO, 2013), precarização dos vínculos de trabalho (BARBOSA, 2017) e desperdícios de recursos, quando não há controle sobre a relação públicoprivada (DIAS et al., 2013).

\section{CONSIDERAÇÕES FINAIS}

Devido à ausência de artigos científicos cujo objetivo era a investigação das limitações do acesso às informações sobre contratação pública em saúde no Brasil, optou-se pela estratégia de revisão de artigos que coligiram informações sobre contratação pública em saúde para diferentes finalidades, e extraiu-se destes artigos os registros dos autores sobre as limitações enfrentadas para o referido acesso.

Verificamos nos estudos analisados que os pesquisadores relatam que essas limitações interferem na aproximação da realidade referente aos objetos centrais de seus estudos, e podem implicar em maiores dispêndios de recursos financeiros e tempo para realização das pesquisas.

Em razão da estratégia de revisão, não foi possível contabilizar os estudos cuja realização foi inviabilizada em decorrência da ausência de acesso à informação, que se configurou como limitação do desenho desta revisão. A escolha dos descritores de busca nas bases de dados para a seleção dos artigos na primeira etapa da coleta de dados também pode representar uma limitação deste estudo e dos seus resultados, visto que não temos uma padronização na comunicação científica dos termos relacionados ao domínio da contratação pública em saúde.

Apesar das limitações desta revisão, foi possível realizar um levantamento das principais dificuldades de acesso às informações sobre contratação pública em saúde à luz de critérios definidos na Lei de Acesso à Informação (BRASIL, 2011), principalmente nas fontes primárias no formato de relatórios técnicos e projetos e pesquisas em andamento, e nas fontes secundárias no formato de bases e bancos de dados tais quais os sistemas de informação em saúde sob gestão do Ministério da Saúde. 


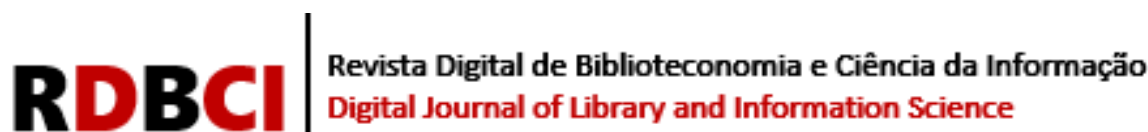

Os pesquisadores registraram dificuldades da qualidade da informação que estava disponível e sua capacidade de permitir o conhecimento sobre a contratação pública investigada, informações que representavam estimativas a partir de instrumentos normativos ou sistemas de informação público, e informações defasadas que se tornavam "fictícias" tamanha a discrepância em relação às informações praticadas.

Foram registradas ainda páginas de internet desatualizadas cuja finalidade era promover transparência informacional do PCP, ausência de registro sobre o fluxo informacional e possíveis substituições e/ou alterações realizadas, informações sem padronização sobre processos de contratação com a mesma finalidade e ausência de informações relacionadas que interferiam nas informações sobre contratação.

As referidas dificuldades apontam para possível fragilidade da fiscalização do cumprimento da Lei de Acesso à Informação, bem como a necessidade de profissionais da informação no setor da saúde pública, incluindo na reconfiguração dos sistemas públicos de informação em saúde para avaliação da contratação pública, e podem servir de subsídio para que, com o apoio das ferramentas teóricas e metodológicas da CI, sejam desenvolvidas estratégias de minimização e/ou liquidação destas dificuldades.

A oferta de um panorama destas dificuldades também pode se configurar como um ponto de partida para futuras pesquisas que aprofundem os critérios de transparência informacional, e que contribuam para o aprimoramento do acesso às fontes de informação com mais registros de limitação por parte dos pesquisadores, direcionados para diferentes públicosalvo destas informações, tais quais pesquisadores, gestores, trabalhadores, prestadores, controladores (internos, externos e social) e usuários do SUS, por exemplo.

A partir do exposto, recomenda-se novos estudos que apresentem propostas de gestão da informação sobre contratação pública em saúde e que o estoque informacional produzido pelo próprio sistema de saúde e instituições contratadas possa ser organizado de modo a contribuir com a recuperação das informações relevantes para a produção de conhecimento científico e tomada de decisão pela gestão do SUS.

\section{CRediT}

RECONHECIMENTOS: Não é aplicável.

FINANCIAMENTO: Não é aplicável.

CONFLITOS DE INTERESSE: Os autores certificam que não têm interesse comercial ou associativo que represente um conflito de interesses em relação ao manuscrito.

APROVAÇÃO ÉTICA: Não é aplicável.

DISPONIBILIDADE DE DADOS E MATERIAL: Não é aplicável.

CONTRIBUIÇÕES DOS AUTORES: Conceituação, Curadoria de Dados, Análise Formal, Investigação, Metodologia, Supervisão, Validação, Visualização, Redação - rascunho original, revisão \& edição: Mota, V.A.; Araújo Júnior, R.H.

\section{REFERÊNCIAS}

ARAÚJO, C. E. L.; GONÇALVES, G. Q.; MACHADO, J. A. Os municípios brasileiros e os gastos próprios com saúde: algumas associações. Ciênc. Saúde Colet., Rio de Janeiro, v. 22, p. 953-963, 2017. Disponível em: https://doi.org/10.1590/1413-81232017223.15542016.

Acesso em: 14 nov. 2020.

ATTARD, J.; ORLANDI, F.; SCERRI, S.; AUER, S. A systematic review of open government data initiatives. Gov Inf Q, Greenwich, v. 32, n. 4, p. 399-418, 2015. Disponível 


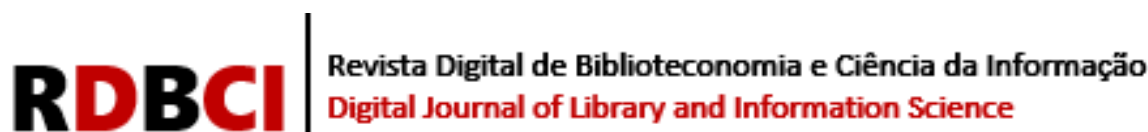

em https://doi.org/10.1016/j.giq.2015.07.006. Acesso em: 27 jan. 2021.

BARATA, R. C. B. Dez coisas que você deveria saber sobre o Qualis. RBPG, Brasília, v. 13, n. 30, p. 13-40, dez. 2016. Disponível em: https://doi.org/10.21713/2358-2332.2016.v13.947. Acesso em: 2 fev. 2021.

BARBOSA, A. C. Q. Vínculos profissionais em hospitais de pequeno porte brasileiros. Rev. adm. empres., São Paulo, v. 57, n. 2, p. 178-195, mar./abr. 2017. Disponível em: https://doi.org/10.1590/s0034-759020170207. Acesso em: 14 nov. 2020.

BASU, S. et al. Comparative performance of private and public healthcare systems in lowand middle-income countries: a systematic review. PLoS med, San Francisco, v. 9, n. 6, p. e1001244, June 2012. Disponível em: https://doi.org/10.1371/journal.pmed.1001244. Acesso em: 14 nov. 2020.

BEVILACQUA, G.; FARIAS, M. R.; BLATT, C. R. Procurement of generic medicines in a medium size municipality. Rev. saúde pública, São Paulo, v. 45, n. 3, p. 583-589, 2011. Disponível em: https://doi.org/10.1590/S0034-89102011005000020. Acesso em: 14 nov. 2020.

BORKO, H. Information science: what is it? American documentation, v. 19, n. 1, p. 3-5, 1968. Disponível em https://doi.org/10.1002/asi.5090190103. Acesso em: 27 jan. 2021.

BRASIL. Decreto n. ${ }^{\circ} 7.724$, de 16 de maio de 2012. Regulamenta a Lei $\mathrm{n}^{\mathrm{o}} 12.527$, de 18 de novembro de 2011, que dispõe sobre o acesso a informações previsto no inciso XXXIII do caput do art. $5^{\circ}$, no inciso II do $\S 3^{\circ}$ do art. 37 e no $\S 2^{\circ}$ do art. 216 da Constituição.

Disponível em http://www.planalto.gov.br/ccivil 03/ato2011-2014/2012/decreto/d7724.htm. Acesso em: 25 abr. 2021.

BRASIL. Lei n. ${ }^{0}$ 12.527, de 18 de novembro de 2011. Regula o acesso a informações previsto no inciso XXXIII do art. $5^{\circ}$, no inciso II do $\S 3^{\circ}$ do art. 37 e no $\S 2^{\circ}$ do art. 216 da Constituição Federal; altera a Lei $n^{\circ} 8.112$, de 11 de dezembro de 1990; revoga a Lei ${ }^{\circ}$ 11.111, de 5 de maio de 2005, e dispositivos da Lei $\mathrm{n}^{\circ} 8.159$, de 8 de janeiro de 1991; e dá outras providências. Disponível em: http://www.planalto.gov.br/ccivil 03/ ato20112014/2011/lei/112527.htm. Acesso em: 14 nov. 2020.

BRASIL. Lei n. ${ }^{\circ}$ 8.666, de 21 de junho de 1993. Regulamenta o art. 37, inciso XXI, da Constituição Federal, institui normas para licitações e contratos da Administração Pública e dá outras providências. Disponível em http://www.planalto.gov.br/ccivil 03/leis/18666cons.htm. Acesso em: 25 abr. 2021.

BRASIL. Política Nacional de Informação e Informática em Saúde. Brasília: Ministério da Saúde, 2016. 56 p. Disponível em:

http://bvsms.saude.gov.br/bvs/publicacoes/politica nacional infor informatica saude 2016.p df. Acesso: 28 abr. 2021.

BUSH, V. As we may think. The Atlantic Monthly, July 1945. Disponível em: https://www.theatlantic.com/magazine/archive/1945/07/as-we-may-think/303881/. Acesso em: 26 jan. 2021. 


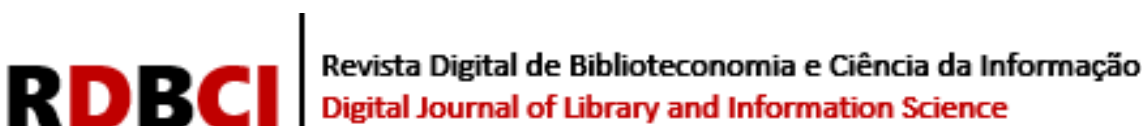

CAMPOS, A. Z. S.; FRANCO, M. P. V. Os efeitos da regulação de preços da CMED sobre as compras públicas de medicamentos do estado de Minas Gerais. Rev. Gest. Sist. Saúde, São Paulo, v. 6, n. 3, p. 253-264, 2017. Disponível em: https://doi.org/10.5585/rgss.v6i3.334. Acesso em: 14 nov. 2020.

CHAVES, G. C.; HASENCLEVER, L.; OLIVEIRA, M. A. Redução de preço de medicamento em situação de monopólio no Sistema Único de Saúde: o caso do Tenofovir. Physis, Rio de Janeiro, v. 28, e280103, 2018. Disponível em: https://doi.org/10.1590/s010373312018280103. Acesso em: 14 nov. 2020.

CHAVES, G. C.; OSORIO-DE-CASTRO, C. G. S.; OLIVEIRA, M. A. Compras públicas de medicamentos para hepatite C no Brasil no período de 2005 a 2015. Ciênc. Saúde Colet., Rio de Janeiro, v. 22, n. 8, p. 2527-2538, 2017. Disponível em: http://dx.doi.org/10.1590/141381232017228.05602017. Acesso em: 14 nov. 2020.

CONTREIRAS, H.; MATTA, G. C. Privatization of health care management through Social Organizations in the city of São Paulo, Brazil: description and analysis of regulation. Cad. saúde pública, Rio de Janeiro, v. 31, n. 2, p. 285-297, 2015. Disponível em: https://doi.org/10.1590/0102-311x00015914. Acesso em: 14 nov. 2020.

COTTA, R. M. M.; CAZAL, M. M.; RODRIGUES, J. F. C. Participação, controle social e exercício da cidadania: a (des) informação como obstáculo à atuação dos conselheiros de saúde. Physis, Rio de Janeiro, v. 19, p. 419-438, 2009. Disponível em: https://doi.org/10.1590/S0103-73312009000200010. Acesso em: 14 nov. 2020.

CUNHA, M. B. Para saber mais: fontes de informação em ciência e tecnologia. Brasília: Briquet de Lemos, 2001. 168 p.

DESGUALDO, C. M.; RIERA, R.; ZUCCHI, P. Estimativa de custo de internação hospitalar de recém-nascidos prematuros em um hospital público terciário no Brasil. Clinics, São Paulo, v. 66, n. 10, p. 1773-1777, 2011. Disponível em:

https://www.scielo.br/scielo.php?script=sci arttext\&pid=S1807-59322011001000016. Acesso em: 14 nov. 2020.

DIAS, L. N. S. et al. Fatores associados ao desperdício de recursos da saúde repassados pela união aos municípios auditados pela Controladoria Geral da União. Rev. Contab. Finanç., São Paulo, v. 24, n. 63, p. 206-218, 2013. Disponível em: https://doi.org/10.1590/S151970772013000300004. Acesso em: 14 nov. 2020.

ELIAS, F. T. S. et al. Treatment options for age-related macular degeneration: a budget impact analysis from the perspective of the Brazilian public health system. PloS One, San Francisco, v. 10, n. 10, p. e0139556, Oct. 2015. Disponível em: https://doi.org/10.1371/journal.pone.0139556. Acesso em: 14 nov. 2020.

EMMERICK, I. C. M. et al. Farmácia Popular Program: changes in geographic accessibility of medicines during ten years of a medicine subsidy policy in Brazil. J Pharm Policy Pract, London, v. 8, n. 1, p. 10, Mar. 2015. Disponível em: https://doi.org/10.1186/s40545-0150030-x. Acesso em: 14 nov. 2020. 


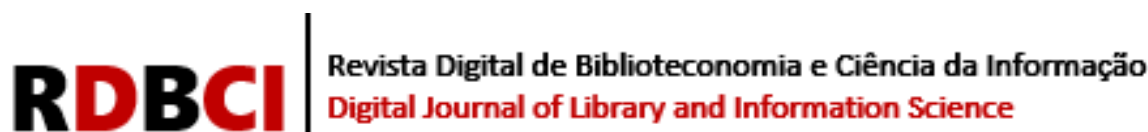

FERREIRA, E. G. A.; SANTOS, E. S.; MACHADO, M. N. Políticas de informação no Brasil: A Lei de Acesso à Informação em foco. MOCI, Belo Horizonte, v. 2, n. 1, 2012. Disponível em: https://periodicos.ufmg.br/index.php/moci/article/view/16940. Acesso em: 27 jan. 2021.

FONSECA, E. M.; COSTA, N. R. Federalismo, complexo econômico-industrial da saúde e assistência farmacêutica de alto custo no Brasil. Ciênc. Saúde Colet., Rio de Janeiro, v. 20, n. 4, p. 1165-1176, 2015. Disponível em: https://doi.org/10.1590/1413-81232015204.00562014. Acesso em: 14 nov. 2020.

FREITAS, M.; MALDONADO, J. M. S. V. O pregão eletrônico e as contratações de serviços contínuos. Rev. Adm. Pública, Rio de Janeiro, v. 47, n. 5, p. 1265-1282, 2013. Disponível em: https://doi.org/10.1590/S0034-76122013000500009. Acesso em: 14 nov. 2020.

FREITAS, R. K. V.; DACORSO, A. L. R. Inovação aberta na gestão pública: análise do plano de ação brasileiro para a Open Government Partnership. Rev. Adm. Pública, Rio de Janeiro, v. 48, n. 4, p. 869-88, 2014. Disponível em: https://doi.org/10.1590/0034-76121545. Acesso em: 14 nov. 2020.

GONZÁLEZ, S. C.; CALIMAN, D. R. Transferência do Gerenciamento de Serviços Públicos de Saúde a Organizações Sociais: Estudo de Caso do Hospital Estadual Central. Rev. Gest. Sist. Saúde, São Paulo, v. 7, n. 2, p. 92-113, 2018. Disponível em: http://www.revistargss.org.br/ojs/index.php/rgss/article/view/316\%20doi. Acesso em: 14 nov. 2020.

GREVE, J.; COELHO, V. S. R. P. Evaluating the impact of contracting out basic health care services in the state of São Paulo, Brazil. Health Policy Plan, Oxford, v. 32, n. 7, p. 923-33, Nov. 2017. Disponível em: https://doi.org/10.1093/heapol/czw176. Acesso em: 14 nov. 2020.

HOMMA, A. et al. Vaccine research, development, and innovation in Brazil: a translational science perspective. Vaccine, Guildford, v. 31, p. B54-B60, Apr. 2013. Disponível em: https://doi.org/10.1016/j.vaccine.2012.11.084. Acesso em: 14 nov. 2020.

IRELAND, M. et al. Expanding the primary health care workforce through contracting with nongovernmental entities: the cases of Bahia and Rio de Janeiro. Hum Resour Health, London, v. 14, n. 1, p. 6, Feb. 2016. Disponível em: https://doi.org/10.1186/s12960-0160101-3. Acesso em: 14 nov. 2020.

JARDIM, J. M. Transparência e opacidade do Estado no Brasil: usos e desusos da informação governamental. Rio de Janeiro: Editora da Universidade Federal Fluminense, 1999. $240 \mathrm{p}$.

JARDIM, J. M. A face oculta do Leviatã: gestão da informação e transparência administrativa. Rev. Serv. Público, Brasília, v. 46, n. 1, p. 137-152, 1995. Disponível em: https://doi.org/10.21874/rsp.v59i1.141. Acesso em: 14 nov. 2020.

KALIKS, R. A. et al. Pacientes com câncer de mama oriundas do Sistema Único de Saúde tratadas no setor privado: custos de um piloto de parceria público-privada em oncologia. 


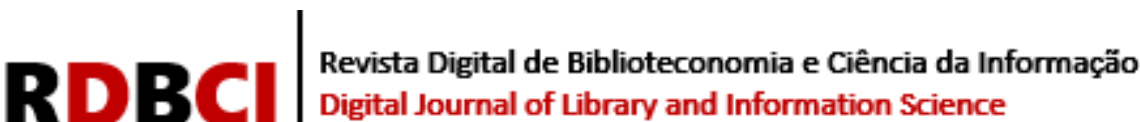

Einstein, São Paulo, v. 11, p. 216-223, 2013. Disponível em: https://doi.org/10.1590/S167945082013000200014. Acesso em: 14 nov. 2020.

KOHLER, J. C. et al. Does pharmaceutical pricing transparency matter? Examining Brazil's public procurement system. Global Health, London, v. 11, n. 1, p. 34, Aug. 2015. Disponível em: https://doi.org/10.1186/s12992-015-0118-8. Acesso em: 14 nov. 2020.

LANSKY, S.; FRANÇA, E.; KAWACHI, I. Social inequalities in perinatal mortality in Belo Horizonte, Brazil: the role of hospital care. Am J Public Health, New York, v. 97, n. 5, p. 867-873, May 2007. Disponível em: https://doi.org/10.2105/AJPH.2005.075986. Acesso em: 14 nov. 2020.

MACKEY, T. K. et al. The disease of corruption: views on how to fight corruption to advance 21 st century global health goals. BMC Med, London, v. 14, n. 1, p 1-16, Sept. 2016. Disponível em: https://doi.org/10.1186/s12916-016-0696-1. Acesso em: 14 nov. 2020.

MATOS, C. A.; POMPEU, J. C. Onde estão os contratos? Análise da relação entre os prestadores privados de serviços de saúde e o SUS. Ciênc. Saúde Colet., Rio de Janeiro, v. 8, p. 629-643, 2003. Disponível em: https://doi.org/10.1590/S1413-81232003000200023.

Acesso em: 14 nov. 2020.

MCGREGOR, A. J.; SIQUEIRA, C. E.; ZASLAVSKY, A. M.; BLENDON, R. J. Do elections matter for private-sector healthcare management in Brazil? An analysis of municipal health policy. BMC Health Serv Res, London, v. 17, n. 1, p. 483, July 2017. Disponível em: https://doi.org/10.1186/s12913-017-2427-5. Acesso em: 14 nov. 2020.

MEINERS, C. et al. Modeling HIV/AIDS drug price determinants in Brazil: is generic competition a myth? PLoS One, San Francisco, v. 6, n. 8, p. e23478, Aug. 2011. Disponível em: https://doi.org/10.1371/journal.pone.0023478. Acesso em: 14 nov. 2020.

MENDES, C. A. et al. Public private partnership in vascular surgery. Einstein, São Paulo, v. 12, n. 3, p. 342-346, 2014. Disponível em: https://doi.org/10.1590/s1679-45082014gs3029. Acesso em: 14 nov. 2020.

MENDES, R. G. O processo de contratação pública: fases, etapas e atos. Curitiba: Zênite, 2012. 348 p.

MERCADO COMUM DO SUL. Protocolo de Contratações Públicas do Mercosul. Brasília, 2017. Disponível em: http://siscomex.gov.br/wp-content/uploads/2020/12/DEC-372017-Protocolo-de-Contratacoes-Publicas.cleaned.docx.pdf. Acesso em: 25 abr. 2021.

MORAES, E. L.; OSORIO-DE-CASTRO, C. G. S.; CAETANO, R. Compras federais de antineoplásicos no Brasil: análise do mesilato de imatinibe, trastuzumabe e L-asparaginase, 2004-2013. Physis, Rio de Janeiro, v. 26, n. 4, p. 1357-1382, 2016. Disponível em: https://doi.org/10.1590/s0103-73312016000400015. Acesso em: 14 nov. 2020.

MORAES, I. H. S. Informações em saúde: da prática fragmentada ao exercício da cidadania. São Paulo: Hucitec, 1994. 172 p. 


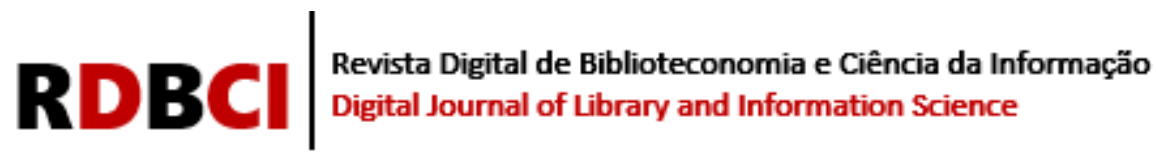

MORAIS, H. M. M. et al. Social healthcare organizations: a phenomenological expression of healthcare privatization in Brazil. Cad. saúde pública, Rio de Janeiro, v. 34, n. 1, p. e00194916, 2018 Feb. 05. Disponível em: https://doi.org/10.1590/0102-311x00194916. Acesso em: 14 nov. 2020.

NUNES, N. K. S.; PAIVA, S. B. Gestão pactuada e dispêndios com pessoal: uma avaliação no Hospital de Traumas da Paraíba à luz da LRF. RC\&C, Curitiba, v. 8, n. 2, p. 108-129, 2016. Disponível em: http://dx.doi.org/10.5380/rcc.v8i2.41401. Acesso em: 14 nov. 2020.

NUNN, A. S. et al. Evolution of antiretroviral drug costs in Brazil in the context of free and universal access to AIDS treatment. PLoS Med, San Francisco, v. 4, n. 11, p. e305, Nov. 2007. Disponível em: https://doi.org/10.1371/journal.pmed.0040305. Acesso em: 14 nov. 2020.

PAIM, J. S. Sistema Único de Saúde (SUS) aos 30 anos. Ciênc. Saúde Colet., Rio de Janeiro, v. 23, n. 6, p. 1723-1728, jun. 2018. Disponível em: https://doi.org/10.1590/141381232018236.09172018. Acesso em: 27 abr. 2021.

PIRES, A. S. et al. The implications of the qualis journal classification in publication practices in brazil between 2007 and 2016. Educ. Policy Anal. Arch., Arizona, v. 28, n. 25, p. 1-25, fev. 2020. Disponível em: https://doi.org/10.14507/epaa.28.4353. Acesso em: 28 abr. 2021.

PONTES, M. A. et al. Aplicação de recursos financeiros para aquisição de medicamentos para atenção básica em municípios brasileiros. Ciênc. Saúde Colet., Rio de Janeiro, v. 22, p. 2453-2462, 2017. Disponível em: https://doi.org/10.1590/1413-81232017228.18282016. Acesso em: 14 nov. 2020.

PRIER, E.; MCCUE, C. P. The implications of a muddled definition of public procurement. J. Public Procure., v. 9, n. 3/4, p. 326-370, Mar. 2009. Disponível em:

https://doi.org/10.1108/JOPP-09-03-04-2009-B002. Acesso em: 14 nov. 2020.

OPEN CONTRACTING PARTNERSHIP. Annual Report 2018. Washington, 2019.

Disponível em: https://www.open-contracting.org/resources/annual-report-2018/. Acesso em: 14 nov. 2020.

OPEN KNOWLEDGE INTERNATIONAL. Global Open Data Index. 2016. Disponível em: https://index.okfn.org/. Acesso em: 14 nov. 2020.

ORGANIZATION FOR ECONOMC CO-OPERATION AND DEVEOPMENT.

Government at a Glance 2015. Paris: OECD Publishing, 2015. Disponível em: https://doi.org/10.1787/22214399. Acesso em: 14 nov. 2020.

ROMANO, C. M. C.; SCATENA, J. H. G. A relação público-privada no SUS: um olhar sobre a assistência ambulatorial de média e alta complexidade na região de saúde da Baixada Cuiabana em Mato Grosso. Rev. Adm. Pública, Rio de Janeiro, v. 48, n. 2, p. 439-458, mar./abr. 2014. Disponível em: https://doi.org/10.1590/0034-76121618. Acesso em: 14 nov. 2020 . 


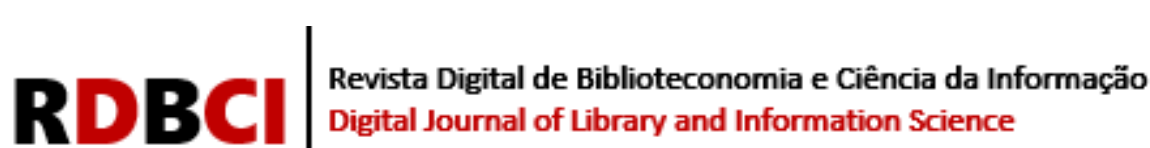

SIGULEM, F.; ZUCCHI, P. E-procurement in the Brazilian healthcare system: the impact of joint drug purchases by a hospital network. Rev Panam Salud Publica, Washington, v. 26, p. 429-434, 2009. Disponível em: https://doi.org/10.1590/S1020-49892009001100007. Acesso em: 14 nov. 2020.

SILVA, R. M.; CAETANO, R. Gastos com pagamentos no Programa Aqui Tem Farmácia Popular: evolução entre 2006-2014. Physis, Rio de Janeiro, v. 28, p. e280105, 2018.

Disponível em: https://doi.org/10.1590/s0103-73312018280105. Acesso em: 14 nov. 2020.

SILVA, E. N. et al. Cost of providing doctors in remote and vulnerable areas: Programa Mais Médicos in Brazil. Rev Panam Salud Publica, Washington, v. 42, p. e11, May 2018. Disponível em: https://doi.org/10.26633/RPSP.2018.11. Acesso em: 14 nov. 2020.

SILVA, V. C.; BARBOSA, P. R.; HORTALE, V. A. Partnerships in Health Systems: Social Organization as limits and possibilities in the Family Health Strategy Management. Ciênc. Saúde Colet., Rio de Janeiro, v. 21, n. 5, p. 1365-1376, May 2016. Disponível em: https://doi.org/10.1590/1413-81232015215.23912015. Acesso em: 14 nov. 2020.

SOUZA, M. T.; SILVA, M. D.; CARVALHO, R. Revisão integrativa: o que é e como fazer. Einstein, São Paulo, v. 8, n. 1, p. 102-106, 2010. Disponível em: https://doi.org/10.1590/s1679-45082010rw1134. Acesso em: 14 nov. 2020.

VIACAVA, F. et al. SUS: oferta, acesso e utilização de serviços de saúde nos últimos 30 anos. Ciênc. Saúde Colet., Rio de Janeiro, v. 23, p. 1751-1762, 2018. Disponível em: http://dx.doi.org/10.1590/1413-81232018236.06022018. Acesso em: 14 nov. 2020.

WHITTEMORE, R.; KNAFL, K. The integrative review: updated methodology. J Adv Nurs, Oxford, v. 52, n. 5, p. 546-553, 2005. Disponível em:

https://onlinelibrary.wiley.com/doi/abs/10.1111/j.1365-2648.2005.03621.x. Acesso em: 18 fev. 2021.

WORLD TRADE ORGANIZATION. WTO Revised Agreement on Government Procurement 2014. Geneva, 2014. 


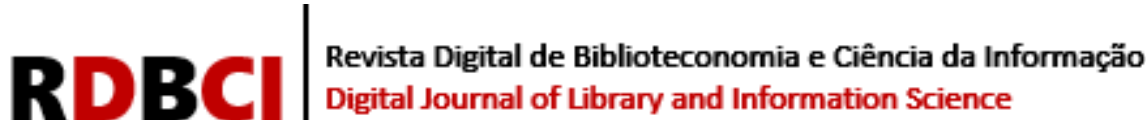

